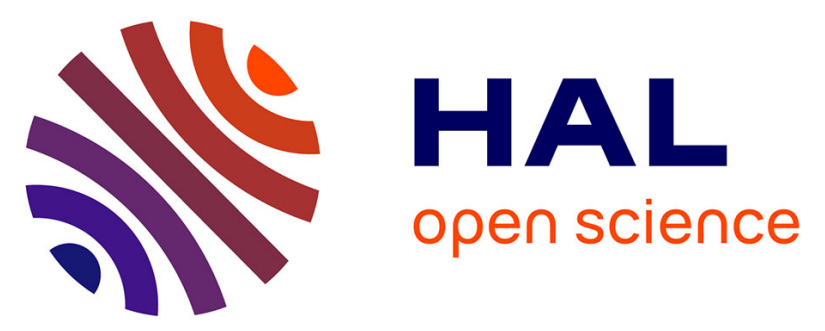

\title{
Complementary variable- and person-centred approaches to the dimensionality of work engagement: a longitudinal investigation
}

Nicolas Gillet, Gaëtane Caesens, Alexandre J.S. Morin, Florence Stinglhamber

\section{- To cite this version:}

Nicolas Gillet, Gaëtane Caesens, Alexandre J.S. Morin, Florence Stinglhamber. Complementary variable- and person-centred approaches to the dimensionality of work engagement: a longitudinal investigation. European Journal of Work and Organizational Psychology, 2019, 28 (2), pp.239-258. 10.1080/1359432X.2019.1575364 . hal-03145618

\author{
HAL Id: hal-03145618 \\ https://hal.science/hal-03145618
}

Submitted on 18 Feb 2021

HAL is a multi-disciplinary open access archive for the deposit and dissemination of scientific research documents, whether they are published or not. The documents may come from teaching and research institutions in France or abroad, or from public or private research centers.
L'archive ouverte pluridisciplinaire HAL, est destinée au dépôt et à la diffusion de documents scientifiques de niveau recherche, publiés ou non, émanant des établissements d'enseignement et de recherche français ou étrangers, des laboratoires publics ou privés. 
Running Head. Work Engagement Profiles

\title{
Complementary Variable- and Person-Centered Approaches to the Dimensionality of Work Engagement: A Longitudinal Investigation
}

Nicolas Gillet*, Département de Psychologie, Université de Tours, France

Gaëtane Caesens*, Université catholique de Louvain, Belgium

Alexandre J.S. Morin, Substantive Methodological Synergy Research Laboratory, Department of Psychology, Concordia University, Canada.

Florence Stinglhamber, Université catholique de Louvain, Belgium

* The first two authors (N.G. \& G.C.) contributed equally to this article and their order was determined at random: Both should thus be considered first authors.

Acknowledgements: This work was supported by the "Fonds de la Recherche Scientifique - FNRS" under grant $\mathrm{n}^{\circ} \mathrm{T} .0177 .16$ awarded to the last author. This article was prepared in part while the second author (G.C.) was a visiting scholar at the Substantive-Methodological Synergy Research Laboratory, Department of Psychology, Concordia University (Canada).

The third author was supported by a grant from the Social Science and Humanity Research Council of Canada (435-2018-0368) in the preparation of this manuscript.

\section{Corresponding author}

Nicolas Gillet,

Université de Tours,

UFR Arts et Sciences Humaines,

Département de psychologie,

3 rue des Tanneurs, 37041 Tours Cedex 1, France.

E-mail: nicolas.gillet@univ-tours.fr

This is the prepublication version of the following manuscript:

Gillet, N., Caesens, G., Morin, A. J. S., \& Stinglhamber, F. (in press). Complementary variable- and person-centered approaches to the dimensionality of work engagement: A longitudinal investigation. European Journal of Work and Organizational Psychology. Early view. doi:

10.1080/1359432X.2019.1575364

This paper is not the copy of record and may not exactly replicate the authoritative document published in European Journal of Work and Organizational Psychology.

\begin{abstract}
This study illustrates complementary variable- and person-centered approaches to the investigation of the underlying dimensionality of the work engagement construct. A sample of 730 participants completed a questionnaire twice across a four-month period. The results showed that employees' ratings of their work engagement simultaneously reflected a global overarching work engagement construct, which co-existed with three specific dimensions (vigor, dedication, and absorption). Relying on factor scores from this initial measurement model, the present study examined latent profiles of employees defined based on their global (work engagement) and specific (vigor, dedication, and absorption) levels of work engagement. The results revealed five distinct work engagement profiles, which proved to be fully identical, and highly stable, across the two time points. These profiles characterized disengaged-vigorous, normative, totally disengaged, vigorously absorbed, and engaged yet distanced employees. These profiles were also showed to be meaningfully related to employees' levels of stress, intentions to leave the organization, health, and job satisfaction.
\end{abstract}

Key words: Work engagement; Latent profiles; Bifactor; Exploratory structural equation modeling; Latent transitions 
The construct of work engagement, typically defined as "a positive, fulfilling, work-related state of mind that is characterized by vigor, dedication, and absorption" (Schaufeli, Salanova, GonzálezRoma, \& Bakker, 2002, p. 74), has received a fair amount of scientific attention in the managerial and organizational sciences (Bakker, 2014; Knight, Patterson, \& Dawson, 2017). Engaged workers possess high levels of energy, work hard, and tend to be involved and happily absorbed in their work (Hakanen, Peeters, \& Schaufeli, 2018). There is a general recognition (Demerouti, Mostert, \& Bakker, 2010; Gillet, Becker, Lafrenière, Huart, \& Fouquereau, 2017) that a complete assessment of work engagement should tap into the three components of vigor (high levels of energy while working, even when performance is challenging), dedication (strong involvement in one's work and a sense of significance, enthusiasm, inspiration, pride, and challenge), and absorption (being fully concentrated on and engrossed in one's work, whereby time passes quickly). However, beyond this recognition, it has been proposed that employees might experience work engagement in a more holistic manner (Schaufeli, Bakker, \& Salanova, 2006) as a single overarching work engagement dimension encompassing elements of vigor, dedication, and absorption (Alessandri, Borgogni, Schaufeli, Caprara, \& Consiglio, 2015; Schaufeli, Shimazu, Hakanen, Salanova, \& De Witte, 2018). This global approach seems to be supported by the observation of high correlations among ratings of vigor, dedication, and absorption (Gillet, Huart, Colombat, \& Fouquereau, 2013; Siu, Bakker, \& Jiang, 2014), and by the fact that a higher-order representation of work engagement tends to relate more strongly to antecedents and outcomes than any of its components (Siu et al., 2014). However, recent findings also suggest that the different components of work engagement present theoretically meaningful and differentiated patterns of associations with a variety of external criteria (Gillet, Becker et al., 2017; Reis, Hoppe, Arndt, \& Lischetzke, 2017).

These observations raise a series of potentially critical questions regarding: (a) whether the work engagement facets of vigor, dedication, and absorption really retain meaningful specificity over and above the assessment of the overarching work engagement construct; and (b) whether this overarching construct exists as a global entity including specificities mapped by the facets, or alternatively whether these facets reflect distinct correlated dimensions without such a common core (Morin, Boudrias et al., 2017). The confirmatory factor analytic (CFA) approach has dominated research focusing on the underlying structure of work engagement (e.g., Costa, Passos, \& Bakker, 2014; Engelbrecht, Heine, \& Mahembe, 2017; Schaufeli et al., 2018). However, CFA includes important restrictions that limit its usefulness when the goal is to conduct a complete investigation of the underlying dimensionality of complex psychological construct such as work engagement. Fortunately, alternative variable- and person-centered approaches exist to support a more thorough investigation of these substantively important questions (e.g., Mäkikangas, Hyvönen, \& Feldt, 2017; Simbula, Guglielmi, Schaufeli, \& Depolo, 2013). The present study is a substantive-methodological synergy (Marsh \& Hau, 2007) aiming to illustrate the utility of these emerging approaches by showing how they may help to achieve an improved perspective on the underlying dimensionality of the work engagement construct. As such, this study has broad relevance to the managerial and organizational sciences by providing the illustration of an overarching variable- and person-centered framework which may be equally applied to investigate the underlying structure of a variety of psychological constructs. The present study more specifically contributes to research on the work engagement construct by: (a) relying on the variablecentered bifactor exploratory structural equation modeling framework to more precisely take into account the inherent multidimensionality of this construct; (b) relying on person-centered analyses to assess the nature of employees' work engagement profiles while taking into account the inherent multidimensionality of this construct; and (c) longitudinally assessing the within-person and withinsample stability of work engagement profiles, and of their relations with key outcome variables.

\section{A Variable-Centered Perspective}

When assessing the structure of responses obtained to typical psychometric measures, the CFA approach provides a way to assess the extent to which our a priori representations match the structure of responses obtained on the instrument, and even to compare alternative representations of the data based on rigorous and objective fit assessment procedures. However, the classical CFA approach relies on the independent cluster assumption that the latent constructs being assessed are unidimensional in nature. More precisely, CFA assumes that ratings obtained on any indicator reflect, or correspond, to scores on a single factor. This assumption has recently been shown to be overly stringent, and often unrealistic, for multiple psychometric measures (e.g., Marsh, Morin, Parker, \& 
Kaur, 2014; Morin, Arens, \& Marsh, 2016; Morin, Arens, Tran, \& Caci, 2016). Morin and colleagues (Morin, Arens, \& Marsh, 2016; Morin, Arens, Tran, \& Caci, 2016; Morin, Boudrias, Marsh, Madore, \& Desrumaux, 2016; Morin, Boudrias et al., 2017) note that whenever multiple conceptually-related constructs are assessed within the same instrument, such as when the vigor, dedication, and absorption components of work engagement are simultaneously assessed, construct-relevant sources of psychometric multidimensionality need to be explicitly taken into account in the model. More precisely, construct-relevant psychometric multidimensionality refers to additional sources of true score variance depicting associations between the items and non-target constructs that, when forcefully ignored in the classical CFA approach, may lead to biased estimates of the model parameters (Asparouhov, Muthén, \& Morin, 2015; Morin, Arens. \& Marsh, 2016).

A first of these common sources of construct-relevant psychometric multidimensionality is particularly relevant to the work engagement construct and refers to the assessment of coexisting global and specific constructs. For instance, in the current debate regarding whether work engagement is best represented as a single global construct (Alessandri et al., 2015; Schaufeli et al., 2018) or as conceptually-distinct subscales (e.g., Demerouti et al., 2010; Gillet, Becker et al., 2017), a third option needs to be considered according to which work engagement might exist both as a global entity reflecting commonalities among ratings of vigor, dedication, and absorption which themselves may include relevant specificity remaining unexplained by this global construct. The higher-order approach suggested by Siu et al. (2014) appears to support the idea that ratings of vigor, dedication, and absorption are indeed conceptually-related dimensions of an underlying global work engagement construct. However, one remaining question is whether sufficient specificity exists in these components (vigor, dedication, and absorption) once the global construct is taken into account.

Psychometrically, two distinct approaches can be used to study this question. The most typical of these approaches relies on hierarchical (i.e., higher-order) factor models (e.g., Rindskopf \& Rose 1988), such as in Siu et al.'s (2014) study. In hierarchical models, ratings on specific items are used to define first-order factors (vigor, dedication, and absorption), which are themselves used to define a higher-order factor (work engagement). However, hierarchical models suffer from one important limitation: They rely on a very stringent proportionality constraint according to which the ratio of variance explained by the global factor (work engagement) relative to that explained by the specific factors (vigor, dedication, and absorption) is forced to be exactly the same for all items associated with a specific first-order factor (Gignac, 2016; Morin, Arens, \& Marsh, 2016; Reise, 2012). Bifactor models provide a more flexible alternative not constrained by this unrealistic proportionality constraint (Brunner, Nagy, \& Wilhelm, 2012; Chen, West, \& Sousa, 2006). In a $f$-factor bifactor model, one Global (G) factor (work engagement) and $f$ - 1 orthogonal Specific (S) factors (vigor, dedication, and absorption) are used to explain the covariance among a set of $n$ items. Bifactor models directly test the presence of a global unitary construct underlying the answers to all items (G-Factor) and whether this global construct co-exists with meaningful specificities (S-Factors) not explained by the G-Factor. Thus, bifactor models provide a way to simultaneously consider both the forest (i.e., the presence of a global level of work engagement) and the trees (i.e., the specificities associated with ratings of vigor, dedication, and absorption) (Tóth-Király, Morin, Bőthe, Orosz, \& Rigó, 2018).

A second common source of construct-relevant psychometric multidimensionality likely to be present in measures of work engagement is related to the fact that specific items designed to assess one specific construct are still likely to present some degree of true score association with non-target constructs (Morin, Arens, \& Marsh, 2016; Morin, Arens, Tran, \& Caci, 2016). For instance, workers' levels of absorption may influence responses to items designed to assess their levels of vigor or dedication due in part to the naturally imperfect nature of these ratings, but also to the fact that work engagement dimensions are inherently interrelated conceptually (Schaufeli et al., 2002, 2006). This form of construct-relevant multidimensionality calls for exploratory factor analyses (EFA) allowing for the free estimation of cross-loadings between items and conceptually-related constructs. EFA has recently been integrated with CFA and structural equation modeling into the exploratory structural equation modeling (ESEM) framework (Marsh et al., 2014; Morin, Marsh, \& Nagengast, 2013), which takes into account the fact that items are generally expected to present at least some degree of valid association with conceptually-related constructs other than the main constructs they are purported to measure (Morin, Arens, \& Marsh, 2016; Morin, Arens, Tran, \& Caci, 2016).

The overarching framework proposed by Morin and colleagues (Morin, Arens, \& Marsh, 2016; 
Morin, Arens, Tran, \& Caci, 2016; Morin, Boudrias et al., 2016, 2017) to identify the sources of construct-relevant multidimensionality present in typical psychometric measures involves the comparison of CFA, ESEM, bifactor-CFA, and bifactor-ESEM models. Importantly, statistical research evidence shows that ignoring any one of these sources of construct-relevant psychometric multidimensionality is likely to result in inflated estimates of factor correlations in CFA, or in inflated estimates of the neglected source of construct-relevant psychometric multidimensionality in ESEM or bifactor models. More precisely, excluding cross-loadings (even as small as .100) from a bifactor model has been shown to result in inflated estimates of the G-factor in bifactor models (e.g., Morin, Arens, \& Marsh, 2016; Murray \& Johnson, 2013) or of factor correlations in CFA (for a review, see Asparouhov et al., 2015). Interestingly, incorporating unnecessary cross-loadings has been shown not to result in estimation biases (Asparouhov et al., 2015). Likewise, ignoring the presence of a global underlying construct is likely to result in inflated estimates of factor correlations in CFA or ESEM models, as well as in inflated estimates of cross-loadings in ESEM (Morin, Arens, \& Marsh, 2016).

The first purpose of the present research is to illustrate, for the first time, the application of this variable-centered framework for the investigation of the dimensionality of the work engagement construct (Schaufeli et al., 2002).

\section{A Complementary Person-Centered Perspective}

Variable-centered analyses, such as the approaches presented in the previous section, operate under the assumption that all participants are drawn from a single population for which a single set of "average" parameters can be estimated. Person-centered analyses, such as latent profile analyses (LPA), explicitly relax this assumption by considering the possibility that the sample might include multiple subpopulations characterized by different sets of parameters (Meyer \& Morin, 2016; Morin, 2016). LPA focus on the identification of subgroups characterized by distinct configurations, or profiles, on a set of variables, and are naturally suited to the consideration of the joint effects of variable combinations. More precisely, LPA provide a way to directly investigate how the various components of work engagement will be combined among different types of employees. Personcentered analyses thus provide a complementary - yet uniquely informative - perspective to variablecentered analyses (Marsh, Lüdtke, Trautwein, \& Morin, 2009; Morin \& Wang, 2016).

Morin and Marsh (2015; also see Morin, Boudrias et al., 2016, 2017) showed that whenever global constructs are assumed to co-exist with specific dimensions assessed from the same set of indicators, failure to control for this global tendency in the context of LPA may mistakenly result in the identification of profiles of employees differing from one another quantitatively (level) rather than qualitatively (shape). More precisely, these authors note that the identification of level-differentiated profiles (i.e., profiles characterized by matching levels across all indicators and differing from one another quantitatively) is generally taken as evidence against the meaningfulness of a person-centered solution, when compared to the identification of shape-differentiated profiles (i.e., profiles characterized by a qualitatively different configuration of indicators). However, just like ignoring the co-existence of global and specific constructs is likely to result in the estimation of inflated factor correlations or cross-loadings in variable-centered analyses, this ignorance is equally likely to result in the erroneous estimation of level-differentiated profiles in LPA. This observation has led Morin, Boudrias et al. $(2016,2017)$ to note that person-centered analyses should be systematically preceded by a comprehensive examination of the psychometric multidimensionality of the indicators used in LPA. They further recommend estimating these LPA on the basis of factor scores estimated from these measurement models, noting that, when compared to more typical scale scores, these factor scores: (a) provide some degree of control for measurement errors (Skrondal \& Laake, 2001); (b) better preserve the characteristics of the underlying measurement model (e.g., multidimensionality, measurement invariance); and (c) in the case of bifactor measurement models, provide a way to identify profiles differing from one another on the basis of both the global and specific factors. This is the approach that will be taken in the present research, which more specifically aims to assess longitudinal variations in employees' profiles of work engagement.

\section{Work Engagement Profiles}

Recently, researchers have started to highlight the importance of considering the combined impact of the different forms of work engagement through the identification of profiles of employees characterized by different work engagement configurations (Mäkikangas \& Kinnunen, 2016; Mäkikangas, Kinnunen, Feldt, \& Schaufeli, 2016). Unfortunately, most of this emerging research has 
focused on the identification of profiles defined based on combinations of work engagement with additional variables (burnout: Mäkikangas et al., 2017; workaholism and burnout: Innanen, Tolvanen, \& Salmela-Aro, 2014; workaholism, burnout, and job satisfaction: Mäkikangas et al., 2015). It is thus not possible, from the results obtained in these studies, to isolate the effects of the different work engagement configurations net of the effects of the additional variables. Most of these studies also only considered global levels of work engagement without considering the specificities associated with the work engagement dimensions.

We located a single person-centered study of direct relevance to the identification of work engagement configurations. In this study, Simbula et al. (2013) relied on cluster analyses to identify teachers' profiles of work engagement based of their levels of vigor, dedication, and absorption. Their results revealed two distinct profiles respectively characterized by high (61.2\% of the participants) or moderate (38.8\% of the participants) levels of vigor, dedication, and absorption. They also found that highly engaged participants showed higher levels of personal development, work-family balance, selfefficacy, job satisfaction, altruism, and civic virtue, and lower levels of health problems relative to moderately engaged participants. These profiles, estimated based on typical scale scores, only display level differences, possibility due to their failure to properly disaggregate global ratings of work engagement from the specificity inherent in the vigor, absorption, and dedication subscales. This study was also limited by its reliance on a sample of teachers, making hard to assess whether these results would generalize to more diversified samples of employees.

However, indirect evidence coming from research conducted on the related-constructs of psychological health and well-being, may prove informative. For instance, Morin, Boudrias et al. (2017) demonstrated the superiority of a bifactor-ESEM representation of employees' ratings of psychological well-being at work. Then, relying on bifactor-ESEM factor scores, results from their LPA revealed four distinct profiles of employees: (1) a normative profile characterized mainly by an average global level of psychological well-being and matching levels across specific dimensions (i.e., interpersonal fit, competence, thriving, involvement, and recognition); (2) an intrinsically-driven profile; (3) an ill-adjusted extrinsically-driven profile; and (4) a well-integrated profile. Similarly, Morin, Boudrias et al.'s (2016) results supported a bifactor-ESEM representation of employees' ratings of psychological health at work (encompassing ratings of well-being and distress). Results from their LPA then revealed a similar five-profile solution including: (a) a normative profile; (b) an adapted profile; (c) a flourishing profile (similar to the previously described well-integrated profile); (d) a stressfully-involved profile (similar to the previously described ill-adjusted extrinsically-driven profile); and (e) a harmoniously-distanced profile.

When considering these results, it is interesting to note both the similarity across studies, and the fact that failure to control for construct-relevant psychometric multidimensionality related to coexisting global and specific constructs may erroneously lead to the identification of leveldifferentiated profiles. Indeed, Morin, Boudrias et al.'s $(2016,2017)$ studies both revealed that profiles identified based on ESEM, rather than bifactor-ESEM, factor scores tended to present almost pure level differences similar to the results obtained by Simbula et al. (2013). In the present study, we apply the methodological framework proposed by Morin, Boudrias et al. $(2016,2017)$ in order to extend Simbula et al.'s (2013) results in the work engagement area. In the absence of prior guidance from work engagement research relying on a proper disaggregation of global versus specific ratings of work engagement in the identification of employees' profiles, we leave as an open research question the expected nature of the profiles that will be identified. However, in line with the consistency of results obtained by Morin, Boudrias et al. $(2016,2017)$ in the study of psychological health and well-being, we expect to identify at least a normative profile characterized by average levels of work engagement across dimensions, an ill-adjusted (totally disengaged) profile characterized by globally low levels of work engagement across dimensions, and a well-integrated (highly engaged) profile characterized by globally low levels of work engagement across dimensions. However, we also expect to identify additional profiles presenting well-differentiated configurations of work engagement across indicators.

\section{A Longitudinal Person-Centered Perspective}

The present study further extends previous research on work engagement by adopting a longitudinal perspective to address the joint issues of within-person profile stability (the stability in the work engagement profiles exhibited by specific individuals over time) and within-sample profile stability (whether the nature of the work engagement profiles changes over time) (Gillet, Morin, \& 
Reeve, 2017; Kam, Morin, Meyer, \& Topolnytsky, 2016). Work engagement has generally been conceptualized as an allegedly stable affective-cognitive state (Mäkikangas et al., 2016; Schaufeli et al., 2002). Indeed, research results have tended to show work engagement trajectories to be relatively stable over time (Mäkikangas, Feldt, Kinnunen, \& Tolvanen, 2012; Mäkikangas, Schaufeli, Tolvanen, $\&$ Feldt, 2013). However, recent evidence suggests that within-person levels of work engagement levels vary over time (Kühnel, Sonnentag, \& Bledow, 2012). A recent variable-centered longitudinal investigation has further demonstrated that the variance in repeated measures of work engagement explained by within-person changes was lower than that explained by within-person stability (Seppälä et al., 2015). Work engagement is thus conceptualized as relatively stable across time with some within-person changes possible over short periods of time. Specifically, the relative ordering of employees based on work engagement ratings is expected to remain stable, even though intraindividual changes can still occur (Perera, Vosicka, Granziera, \& McIlveen, 2018). However, as recently demonstrated in a meta-analysis (Lesener, Gusy, \& Wolter, 2018), job characteristics (e.g., job resources) may explain changes in work engagement over time (also see Huyghebaert et al., 2018).

It remains unclear to what extent these variable-centered results might generalize to the personcentered context, and to properly disaggregated ratings of global versus specific ratings of work engagement. Thus, a variable-centered increase in average levels of work engagement could be translated into: (a) a greater tendency for employees to transition to profiles characterized by higher levels of work engagement (a within-person source of instability); (b) modifications in the nature of profiles so that they become characterized by higher levels of work engagement (a within-sample source instability); and (c) increases in the relative size of profiles characterized by higher levels of work engagement (another source of within-sample instability). Thus, although previous results lead us to expect high levels of stability and moderate levels of change over time, we leave as an open question whether changes will be mainly expressed at the within-person or within-sample level.

\section{A Person-Centered Construct Validation Perspective}

In person-centered research, in order to be able to support a substantive interpretation of latent profiles as being relevant, it is critical to embark on a process of construct validation aiming to demonstrate that the profiles present meaningfully differentiated associations with key outcome variables (Marsh et al., 2009; Meyer \& Morin, 2016; Morin \& Wang, 2016). Thus, a final goal of the present research is to assess the extent to which work engagement profiles will be related to a series of outcome variables: Intentions to quit (employees' intentions to leave their organization), job satisfaction (a feeling of fulfilment or enjoyment that workers derive from their job), health (a state of complete physical, mental, and social well-being), and stress (employees' response when job demands do not match with their knowledge and abilities). These variables were retained based on research evidence showing that they present significant associations with work engagement (Caesens, Stinglhamber, \& Marmier, 2016; Steffens, Yang, Jetten, Haslam, \& Lipponen, 2018). Given its role as a psychological resource for employees (Halbesleben, 2010), it is not surprising to note that previous variable-centered research has shown work engagement to be associated with a variety of outcome variables known to be beneficial for both the organization (e.g., lower levels of turnover intentions; Halbesleben, 2010) and the employee (e.g., higher job satisfaction, better self-perceived health, lower stress; Schaufeli \& Bakker, 2004). For instance, past studies have demonstrated that work engagement is fundamental to, and a predictor of, important aspects of organizational behavior, including employees' intentions to quit their organization (Halbesleben, 2010). Highly engaged employees tend to have more positive emotions and think about their work more positively (Bakker, 2014).

Fredrickson (2001) argued that these positive emotions bring employees to increase their identification with the organization and their willingness to allocate extra time and resources to their organization. In such cases, employees' turnover intentions are thus lower. Intentions to leave the organization may also be a form of coping strategy used to deal with low work engagement (Caesens et al., 2016).

The assumption that the identified latent profiles will demonstrate construct validity lead us to expect well-differentiated relations between the identified work engagement profiles and the work outcomes considered in this study. However, the lack of previous research conducted in this area makes it hard to provide more specific hypotheses in this regard. Research has generally shown that, when considered in isolation, vigor, dedication, and absorption all represent key drivers of desirable outcomes such as job satisfaction and health (Bakker, 2014). However, these studies are limited by their failure to consider the possible combined effects of these work engagement components. In 
particular, despite the acknowledgement that employees and organizations might benefit from higher levels of work engagement, little is known about the typical configurations that characterize these combinations and their effects on employee's well-being, attitudes, and behaviors (Simbula et al., 2013). Moreover, past studies did not rely on a bifactor representation of employees' ratings of work engagement, and thus did not consider global levels of work engagement and specific levels of vigor, dedication, and absorption when identifying the profiles. Indeed, although Simbula et al. (2013) also considered some of the specific outcomes considered in this study (i.e., health and job satisfaction), the nature of the profiles identified in their study only allows us to expect profiles characterized by higher levels of work engagement to be associated with more adaptive outcomes than profiles characterized by lower levels of engagement. The present study addresses these gaps through the adoption of an approach allowing us to: (1) identify employees' profiles characterized by distinct configurations of global and specific work engagement components; and (2) examine the associations between these configurations and a series of work-related outcomes known to be associated with work engagement. Contrary to a variable-centered approach, this person-centered approach may allow us, for instance, to answer to the following question: Is a profile with low levels of global work engagement, dedication, and absorption, and high levels of vigor associated with more positive outcomes than a profile with low levels of global work engagement, dedication, absorption, and vigor?

\section{Participants and Procedure}

\section{Method}

Participants from Prolific Academic, a UK crowdsourcing platform, were invited to complete two online questionnaires, one in November 2016 (Time 1) and one four months later in March 2017 (Time 2). Each time, participants were informed of the objectives of the project, that their participation was voluntary, that they could withdraw from the project at any time, and that their responses were confidential. Each participant was paid $£ 1.50$ as a compensation for the time spent completing the questionnaire (approximately 15 minutes) at each time point. In order to match participants' responses at both time points while maintaining confidentiality, participants were asked to provide a unique personal code. This project was approved by the University Research Ethics committee.

Pre-screening criteria were set to recruit only participants who: (1) had a minimum approval rate of $90 \%$ in prior tasks completed on Prolific Academic (i.e., an indicator of trustworthiness), (2) spoke English as their first language, (3) were working full-time or part-time, and (4) were not selfemployed. Indeed, because self-employed persons work for themselves rather than for an employer, they could not answer to questions related to their intentions to quit the organization. Because they tend to value personal challenge to a greater extent (Warr \& Inceoglu, 2017), self-employed professionals also tend to present higher levels of work engagement than workers employed by an organization. A total of 799 participants completed the first questionnaire (Time 1) and 599 participants completed the second questionnaire four months later (Time 2), for a follow-up rate of $74.9 \%$. The survey included two questions aiming to assess their degree of attention during completion (e.g., "it is important that you pay attention to our survey. Please tick strongly disagree"). At the end of the questionnaire, participants were also asked to indicate, "for scientific reasons", if they were really working for an organization. Once participants who failed one of those verification questions were excluded, the final sample included 730 participants who completed Time 1 measures and 525 who completed Time 2 measures. Of those participants, $47.53 \%$ were women, their average age was 34.95 years $(S D=10.70)$, most had a bachelor degree $(46.44 \%)$, and they had been working for their organization for an average of 5.99 years $(S D=6.14)$. When the 525 participants were compared with those who completed both time points on the Time 1 measures, no statistically significant differences emerged on any of the main study variables or in terms of education level $(p \geq .05)$, and only a few differences emerged on the demographic variables revealing that participants lost to attrition tended to be younger $(p \leq .001)$, to have less tenure $(p \leq .001)$, and more frequently females $(p=.024)$.

\section{Measures}

Work engagement. The Utrecht Work Engagement Scale (UWES-17; Schaufeli et al., 2002) was used to assess work engagement. This instrument includes three subscales assessing vigor ( 6 items; $\alpha$ $=.84$ at Time 1 and .87 at Time 2; e.g., "At my work, I feel bursting with energy"), dedication (5 items; $\alpha=.91$ at Time 1 and .91 at Time 2; e.g., "I am enthusiastic about my work"), and absorption (6 items; $\alpha=.86$ at Time 1 and .87 at Time 2; e.g., "I am immersed in my work"). These items were rated on a 7-point Likert-type scale ranging from 1 ("Never") to 7 ("Always"). 
Intentions to quit the organization. Participants' intentions to leave employment with their organization were assessed using 3 items developed by Jaros $(1997 ; \alpha=.93$ at Time 1 and .94 at Time 2; e.g., "I often think about quitting this organization"). These items were rated on a 7-point Likerttype scale ranging from 1 ("Strongly disagree") to 7 ("Strongly agree").

Job satisfaction. Job satisfaction was assessed using a 4-item scale developed by Eisenberger, Cummings, Armeli, and Lynch (1997; $\alpha=.93$ at Time 1 and .94 at Time 2; e.g., "All in all, I am very satisfied with my current job"). These items were rated on a 7-point Likert-type scale ranging from 1 ("Strongly disagree") to 7 ("Strongly agree").

Health. Employees' perceptions of their general health were assessed using 2 items taken from the Self-Assessed Health Status (SAHS) (Ettner, 1996; Saunders, 1996). Participants were first invited to rate their overall health on a 5-point Likert type scale ranging from 1 ("Very bad") to 5 ("Very good"), before being invited to rate their present state of health when compared to the last year on a on a 5-point Likert type scale ranging from 1 ("Much worse") to 5 ("Much better"). Given the wellknown positive relation between the number of items forming a scale and estimates of scale score reliability (e.g., Streiner, 2003), it is not surprising to note that these estimates were low for this subscale ( $\alpha=.50$ at Time 1 and .52 at Time 2$)$. This low level of reliability reinforces the importance of relying on analyses providing at least some degree of control for measurement errors. However, when we rely on the Spearman-Brown prophecy formula (Nunnally \& Bernstein, 1994) to estimate the value these reliability coefficients would take based on eight equivalent indicators $(\alpha=.80$ at Time 1 and .81 at Time 2), these low estimates appear to mainly reflect the reduced length of the scale.

Stress. A single-item measure was used to assess employees' levels of stress (Coetsier et al., 1996; Pelfrene et al., 2002). More precisely, participants were asked to indicate "To what extent do you feel generally stressed at work" using a 4-point Likert scale, ranging from 1 ("Very stressed") to 4 ("Not at all stressed"). Scores on this item were recoded prior to the analyses to ensure that higher scores on this variable reflected the presence of higher levels of stress.

\section{Analyses}

\section{Model Estimation}

In this study, all models were estimated using Mplus 8 (Muthén \& Muthén, 2017) robust Maximum Likelihood (MLR) estimator, which provides parameter estimates, standard errors, and goodness-of-fit that are robust to the non-normality of the response scales used in the present study (Finney \& DiStefano, 2013). These models were estimated with Full Information Maximum Likelihood (FIML; Enders, 2010) in order to be able to rely on the full sample of participants who completed at least one measurement point $(N=730)$, rather than a listwise deletion strategy focusing on the subset of participants $(N=485)$ who answered both time points. Due to the way the online testing was set up, there were no missing data at the item levels for participants who completed each time point). FIML has comparable efficacy to multiple imputation, while being more computationally efficient (Enders, 2010; Graham, 2009; Jeličič, Phelps, \& Lerner, 2009; Larsen, 2011).

\section{Variable-Centered Analyses}

CFA, bifactor-CFA, ESEM, and bifactor-ESEM representations of responses to the work engagement measure were separately estimated at each time point following Morin et al.'s (Morin, Arens, \& Marsh, 2016; Morin, Arens, Tran, \& Caci, 2016; Morin, Boudrias et al., 2016, 2017) recommendations. In CFA, each item was only allowed to load on the factor it was assumed to measure, and no cross-loadings were allowed. This model included three correlated factors representing vigor, dedication, and absorption. In ESEM, the same set of three factors was represented using a confirmatory oblique target rotation (Asparouhov \& Muthén, 2009; Browne, 2001). Target rotation makes it possible to freely estimate all main loadings while constraining all cross-loadings to be as close to zero as possible. In bifactor-CFA, all items were allowed to simultaneously load on one G-factor reflecting global levels of work engagement, and on three S-factors corresponding to specific levels of vigor, dedication, and absorption. No cross-loadings were allowed between the S-factors, and all factors were specified as orthogonal in line with bifactor assumptions (e.g., Morin, Arens, \& Marsh, 2016; Morin, Arens, Tran, \& Caci, 2016; Reise, 2012). Bifactor-ESEM estimated the same set of G- and S-factors as the bifactor-CFA solution, while allowing for the free estimation of cross-loadings between the S-factors using an orthogonal bifactor target rotation (Morin, Arens, \& Marsh, 2016; Reise, Moore, \& Maydeu-Olivares, 2011).

Given the known oversensitivity of the chi-square test of exact fit to sample size and minor model misspecifications (Marsh, Hau, \& Grayson, 2005), we relied on goodness-of-fit indices to describe the 
fit of the alternative models: the comparative fit index (CFI), the Tucker-Lewis index (TLI), and the root mean square error of approximation (RMSEA) with its $90 \%$ confidence interval. According to typical interpretation guidelines (e.g., Hu \& Bentler, 1999; Marsh, Hau, \& Wen, 2004; Marsh et al., 2005), values greater than .90 and .95 for the CFI and TLI respectively are considered to be indicative of adequate and excellent fit to the data, while values smaller than .08 or .06 for the RMSEA respectively support acceptable and excellent model fit. In the comparison of nested models (such as in the tests of measurement invariance to be described shortly), typical guidelines suggest that models differing from one another by less than .01 on the CFI and TLI, or .015 on the RMSEA, can be considered to provide an equivalent level of fit (Chen, 2007; Cheung \& Rensvold, 2002).

As noted by Morin and colleagues (Morin, Arens, \& Marsh, 2016; Morin, Arens, Tran, \& Caci, 2016; Morin, Boudrias et al., 2016, 2017), fit indices are not sufficient to guide the selection of the optimal model. Indeed, each of these alternative models is able to absorb sources of construct-relevant multidimensionality left unmodelled, thus hiding sources of misfit behind apparently similarly fitting models (Asparouhov et al., 2015; Morin, Arens, \& Marsh, 2016; Murray \& Johnson, 2013). Thus, unmodelled cross-loadings tend to result in inflated factor correlations in CFA, or inflated G-factor loadings in bifactorCFA. Likewise, an unmodelled G-factor tends to produce inflated factor correlations in CFA or inflated cross-loadings in ESEM. For this reason, an examination of parameter estimates and theoretical conformity is required to select the best alternative. As suggested by Morin and colleagues (Morin, Arens, \& Marsh, 2016; Morin, Arens, Tran, \& Caci, 2016; Morin, Boudrias et al., 2016, 2017), model comparison should always start by contrasting CFA and ESEM solutions. Here, statistical evidence shows that ESEM provides more exact estimates of factor correlations when cross-loadings are present in the population model while remaining unbiased otherwise (Asparouhov et al., 2015). For this reason, as long as the factors remain welldefined, observing a distinct pattern of factor correlations should be taken as support for the ESEM solution. The second step involves contrasting the retained CFA or ESEM solution with a bifactor alternative. Here, the key elements supporting the bifactor representation are the observation of: (1) an improved level of fit to the data; (2) a well-defined G-factor; and (3) at least some reasonably well-defined S-factors. The observation of multiple large (e.g., $\geq .300$ ) cross-loadings in ESEM that are reduced in bifactor-ESEM represents an additional source of evidence in favor of the bifactor solution (Morin, Arens, \& Marsh, 2016). For all models, we thus report standardized parameter estimates, as well as composite reliability coefficients associated with each of the a priori factors are calculated from the model standardized parameters using McDonald (1970) omega ( $\omega)$ :

$$
\omega=\frac{\left(\sum\left|\lambda_{i}\right|\right)^{2}}{\left[\left(\sum\left|\lambda_{i}\right|\right)^{2}+\sum \delta_{i}\right]}
$$

where $\left|\lambda_{i}\right|$ are the standardized factor loadings associated with a factor in absolute values, and $\delta i$, the item uniquenesses.

Based on the final retained measurement model, we then proceeded to tests of measurement invariance across time points (Millsap, 2011): (a) configural invariance, (b) weak invariance (loadings), (c) strong invariance (loadings, intercepts), (d) strict invariance (loadings, intercepts, uniquenesses), (e) invariance of the latent variances-covariances (loadings, intercepts, uniquenesses, variances-covariances), and (f) latent means invariance (loadings, intercepts, uniquenesses, variances-covariances, latent means). A priori correlated uniquenesses between matching indicators of the factors utilized at the different time points were included in these longitudinal models to avoid inflated stability estimates (Marsh, 2007). Factor scores were then saved from the most invariant measurement model and used as inputs for the personcentered analyses (for additional details on the advantages of factor scores, see Meyer \& Morin, 2016; Morin, Meyer, Creusier, \& Biétry, 2016). Although factor scores do not fully control for measurement errors the way latent variables do, they provide a partial control for those errors by giving more weight to items presenting lower levels of measurement errors (Skrondal \& Laake, 2001), and preserve the underlying nature of the measurement model (e.g., invariance) better than scale scores (Morin, Boudrias et al., 2016, 2017; Morin, Meyer et al., 2016).

\section{Person-Centered Analyses}

LPA were first estimated separately at each time point using the work engagement factor scores as profile indicators to verify whether the same number of profiles would be extracted at both time points (Morin \& Wang, 2016). At each time point, we examined solutions including one to 10 profiles in which the means of the work engagement factor scores were freely estimated in all profiles. Despite the advantages of models in which the indicators' variances are also freely estimated (Morin et al., 2011; 
Peugh \& Fan, 2013), these alternative models converge on improper solutions (e.g., negative variance estimates, non-positive definite Fisher Information matrix) or failed to converge in the present study. This suggests their overparameterization and the superiority of our more parsimonious models (Bauer \& Curran, 2003; Chen, Bollen, Paxton, Curran, \& Kirby, 2001). To avoid local maximum, timespecific LPA were estimated using 5000 random sets of start values, 1000 iterations, and retained the 200 best solutions for final stage optimization (Hipp \& Bauer, 2006; McLachlan \& Peel, 2000). These values were increased to 10000,1000 , and 500 for the longitudinal models.

To determine the optimal number of profiles at both time points, multiple sources of information need to be considered, including the examination of the substantive meaningfulness, theoretical conformity, and statistical adequacy of the solutions (Marsh et al., 2009; Morin, 2016; Muthén, 2003). Statistical indices are available to support this decision (McLachlan \& Peel, 2000): (i) The Akaïke Information Criterion (AIC), (ii) the Consistent AIC (CAIC), (iii) the Bayesian Information Criterion (BIC), (iv) the sample-size Adjusted BIC (ABIC), (v) the standard and adjusted Lo, Mendell and Rubin's (2001) Likelihood Ratio Tests (LMR/aLMR; as these tests typically yield the same conclusions, we only report the aLMR), and (vi) the Bootstrap Likelihood Ratio Test (BLRT). A lower value on the AIC, CAIC, BIC, and ABIC suggests a better-fitting model. The aLMR and BLRT compare a $k$-class model with a $k$ - 1 -class model. A significant $p$ value indicates that the $k$ - 1 -class model should be rejected in favor of a $k$-class model.

Simulation studies indicate that four of these indicators (CAIC, BIC, ABIC, and BLRT) are particularly effective (Henson, Reise, \& Kim, 2007; Nylund, Asparouhov, \& Muthén, 2007; Peugh \& Fan, 2013; Tein, Coxe, \& Cham, 2013; Tofighi \& Enders, 2008), while the AIC and LMR/ALMR should not be used in the class enumeration process as they respectively tend to over- and underextract incorrect number of profiles (Diallo, Morin, \& Lu, 2016, 2017; Henson et al., 2007; Nylund et al., 2007; Peugh \& Fan, 2013; Tofighi \& Enders, 2008). These indicators will thus be reported only to ensure a complete disclosure, but will not be used to select the optimal number of profiles. It should be noted that these tests remain heavily influenced by sample size (Marsh et al., 2009), so that with sufficiently large samples, they may keep on suggesting the addition of profiles without reaching a minimum. In this situation, the point at which these indicators appear to reach a plateau can be used to suggest the optimal solution (Morin et al., 2011). The entropy indicates the precision with which the cases are classified into the various profiles. The entropy should not be used to determine the optimal number of profiles (Lubke \& Muthén, 2007), but serves to summarize classification accuracy (0 to 1), with higher values indicating more accuracy.

Once the optimal number of profiles had been selected at each time point, we integrated the two retained LPA solutions (one per time point) into a single longitudinal LPA model allowing for systematic longitudinal tests of profile similarity. These tests were conducted following the sequential strategy proposed by Morin, Meyer et al. (2016) for tests of profile similarity across multiple groups and recently optimized by Morin and Litalien (2017) for the longitudinal context. The first step examines whether the same number of profiles can be identified at each time point (i.e., configural similarity) and corresponds to the previously described time-specific LPA. Starting from this longitudinal model of configural similarity, equality constraints are then progressively integrated. In the second step, the structural similarity of the profiles is verified by including equality constraints across time points on the means of the profile indicators (i.e., the work engagement factors) to test whether the profiles retain the same global shape across time points. If this form of similarity holds, then the third step tests the dispersion similarity of the profiles by including equality constraints across time points on the variances of the profile indicators to verify whether the within-profile variability remains similar across time. Fourth, starting from the most similar model from the previous sequence, the distributional similarity of the profiles is tested by constraining the class probabilities to equality across time points to test whether the relative size of the profiles remains the same. The fit of these models can be compared using the aforementioned information criteria. Morin, Meyer et al. (2016) also suggest that at least two indices out of the CAIC, BIC, and ABIC should be lower for the more "similar" model for the hypothesis of profile similarity to be supported.

Longitudinal Person-Centered Analyses and Profile Transitions. The most similar model from the previous sequence was then converted to a longitudinal latent transition analysis (LTA) model (Collins \& Lanza, 2010; Nylund et al., 2007), to investigate within-person stability and transitions in profile membership. This sequence was then extended to tests of predictive and explanatory similarity 
to investigate whether the associations between the profiles and, respectively, their predictors and outcomes remained the same across time points. Following Morin and Litalien's (2017) recommendations, all LTA were estimated using the manual auxiliary 3-step approach described by Asparouhov and Muthén (2014).

Predictors and Outcomes of Profile Membership. In this study, demographic variables (age, sex, and organizational tenure) were incorporated to the final model to investigate the need to retain these variables as controls for the subsequent analyses and, if this is the case, whether the relations between these variables and profile membership would remain unchanged over time. The decision to consider these demographic variables as possible controls for the analyses conducted here stems from previous research evidence showing positive associations between work engagement and age (Camgoz, Ekmekci, Karapinar, \& Guler, 2016; Rudolph \& Baltes, 2017), organizational tenure (Bal \& de Lange, 2015), and female gender (Camgoz et al., 2016). Multinomial logistic regressions were conducted to test the relations between these demographic characteristics and the likelihood of membership into the various profiles. In these analyses, the demographic controls were allowed to predict the profiles estimated at both time points. Four alternative models were contrasted. First, we considered a null effects model in which the relations between the predictors and profile membership were constrained to be exactly zero at both time points. Second, relations between predictors and profile membership were freely estimated across time points, and predictions of Time 2 profile membership were allowed to vary across Time 1 profiles (to test whether the effects of predictors on profile transitions differed across profiles). Third, predictions were freely estimated across time, but not profiles. Finally, the predictive similarity of the model was tested by constraining predictions to equality across time points.

Outcomes were also incorporated into the final LTA solution. In these analyses, measures of the various outcomes (intentions to quit, job satisfaction, health, and stress) taken at both time points were simultaneously included to the model and specified as associated with the profiles estimated at the matching time point. We used the MODEL CONSTRAINT command of Mplus to systematically test mean-level differences across pairs of profiles using the multivariate delta method in a single analytical step (Kam et al., 2016; Raykov \& Marcoulides, 2004). We then proceeded to tests of explanatory similarity by constraining the within-profile means of these outcomes to equality across time points. All outcomes assessed on the basis of multiple-item measures (intentions to quit, job satisfaction, health) were incorporated to these models as factor scores saved from longitudinally invariant preliminary measurement models. In these models, each outcome was defined as a simple correlated CFA factor. A priori correlated uniquenesses between matching indicators of the factors utilized at the different time points were included in these longitudinal models to avoid inflated stability estimates (Marsh, 2007). Because the health factor was estimated from only two indicators, thus creating a locally underidentified factor, this factor was locally-identified using essentially tauequivalent constraints (ETEC; Little, Lindenberger \& Nesselroade, 1999). This technique involves placing equality constraints on the loadings of both indicators to help locate the construct at the true intersection of the indicators. The results from these additional measurement models are reported in Tables S1 and S2 of the online supplements, and the correlations among all variables are reported in Table S3 of these online supplements.

\section{Variable-Centered Analyses}

\section{Results}

Table 1 presents the goodness-of-fit indices of the various models, at both time points. The CFA model failed to achieve an acceptable level of fit at both time points according to the TLI $(\leq .900)$ and RMSEA (> .080), as well as at Time 1 according to the CFI $(\leq .900)$. Similarly, whereas the bifactorCFA model achieved an acceptable level of fit at Time 1 based on all goodness-of-fit indices, it failed to do so at Time 2 based on the TLI $(\leq .900)$ and RMSEA $(>.080)$. In contrast, both the ESEM and bifactor-ESEM solutions were able to achieve an acceptable level of fit to the data at both time points according to all goodness-of-fit indices. Moreover, the bifactor-ESEM resulted in a substantial increase in model fit relative to the ESEM results at both time points according to the CFI $(\triangle \mathrm{CFI}=$ +.014 at Time 1 and +.026 at Time 2$)$ and TLI $(\Delta \mathrm{TLI}=+.014$ at Time 1 and +.031 at Time 2$)$. Based strictly on this statistical information, the bifactor-ESEM solution should be retained, unless the GFactor estimated as part of this solution proved to be meaningless (i.e., weakly defined through low factor loadings). If this was the case, then the ESEM model would represent a viable alternative. 
However, as noted above, model selection should always be based on a complete examination of the parameter estimates and theoretical conformity of each solution. Thus, we first compared the CFA and ESEM solutions, before comparing the ESEM and bifactor-ESEM solutions.

ESEM versus CFA. Parameter estimates for the CFA and ESEM solutions are available in Table S4 of the online supplements, and factor correlations for these solutions are reported in Table S5 of the online supplements. Looking first at the CFA solutions, it is noteworthy that all factors appeared to be well-defined by strong factor loadings at both time points $\left(|\lambda|=.410\right.$ to $\left..910 ; M_{|\lambda|}=.742\right)$. In contrast, when we look at the ESEM solutions, the absorption factor appeared to be relatively weakly defined at both time points $\left(|\lambda|=.144\right.$ to $\left..509 ; M_{|\lambda|}=.320\right)$, and the vigor factor similarly appeared to be weakly defined at Time $2\left(|\lambda|=.039\right.$ to $\left..743 ; M_{|\lambda|}=.395\right)$. In contrast, the dedication factor was well-defined at both time points $\left(|\lambda|=.531\right.$ to $\left..867 ; M_{|\lambda|}=.709\right)$, and the vigor factor was similarly well-defined at Time $1\left(|\lambda|=.382\right.$ to $\left..840 ; M_{|\lambda|}=.569\right)$. Looking more carefully at the ESEM solutions, multiple crossloadings of a relatively strong magnitude were apparent (there were 13 cross-loadings higher than .300 in the Time 1 ESEM solution, relative to nine in the Time 2 solution), and appeared to contribute to the weak definition of the vigor and dedication factors, given that the a priori indicators of both of these factors presented multiple cross-loadings on non-target factors. The presence of multiple crossloadings reinforced the need to incorporate this source of construct-relevant psychometric multidimensionality to the model. They also argued against this specific ESEM solution, strongly suggesting that a global factor might need to be incorporated to the model. Examination of the factor correlations associated with both of these solutions similarly reinforced the need to incorporate crossloadings to the model, as these appear to be substantially reduced in the ESEM ( $r=.344$ to $.743, M_{r}=$ $.544)$ relative to CFA solutions ( $r=.899$ to $\left..935, M_{r}=.924\right)$ in which these correlations were high enough to suggest conceptual redundancy among factors.

ESEM versus Bifactor-ESEM. The parameter estimates from the bifactor solutions are reported in Table 2. The results from the bifactor-ESEM solutions revealed a G-Factor well-defined by strong and positive loadings from most items at both time points $\left(|\lambda|=.355\right.$ to $\left..884 ; M_{\lambda}=.717\right)$. Over and above this G-Factor, the items defining these S-Factors presented a weaker association with their SFactor than with the G-Factor. However, all S-Factors retained at least some specificity once the GFactor was taken into account in the model (vigor: $|\lambda|=.137$ to $.523 ; M_{|\lambda|}=.272$; dedication: $|\lambda|=.185$ to $.397 ; M_{|\lambda|}=.324$; absorption: $|\lambda|=.010$ to $\left..534 ; M_{|\lambda|}=.228\right)$. This last affirmation was supported by the estimation of composite reliability coefficients of an acceptable magnitude for both the vigor $(\omega=$ .606 at Time 1 and .622 at Time 2$)$ and dedication $(\omega=.648$ at Time 1 and .672 at Time 2$)$ S-factors. In contrast, the reliability of scores on the absorption S-factors was lower $(\omega=.391$ at Time 1 and .378 at Time 2). It should also be kept in mind that all target loadings on the S-Factors remained statistically significant even they were not defined as strongly as the G-factor. These results support the need to control for their content specificity in the model. The fact that these S-Factors retain less specificity than the other factors does not signify that this specificity is not meaningful especially when modelled using an approach that explicitly controls for both measurement errors and associations with the global engagement construct, such as the approach taken in the present study. The superiority of the bifactor-ESEM solutions was also apparent from the substantially reduced cross-loadings (i.e., a single cross-loading remained higher than .300, and only marginally so).

Measurement Invariance. The bifactor-ESEM solution was thus retained at both time points as our final solution and used to realize tests of measurement invariance across time points. The results from these tests are reported in the bottom section of Table 1 and supported the complete measurement invariance of this solution as none of the changes in goodness-of-fit indices exceeded the recommended guidelines. Factor scores for the person-centered analyses were thus extracted from the model of complete measurement invariance. Only strict measurement invariance is required to ensure that measurement of the constructs remains equivalent across time waves for models based on factor scores (e.g., Millsap, 2011). However, there are advantages to saving factor scores from a model of complete measurement invariance, which provides time-specific measures which are directly comparable based on a mean of 0 and a standard deviation of 1 at all time waves.

\section{Person-Centered Analyses}

Latent Profile Solutions. The fit indices associated with the LPA estimated separately at both time points are reported in Table $\mathrm{S} 6$ of the online supplements, and the elbow plots associated with these results are presented in Figures S1 and S2 of the online supplements. Examination of these 
results revealed that, at both time points, the ABIC kept on improving with the addition of profiles to the solution, without reaching a minimum, whereas the BLRT supported the nine-profile solution at Time 1 and the seven-profile solution at Time 2. In contrast, the CAIC and BIC respectively supported the four- and five-profile solutions at Time 1 . These indices also supported the three-profile solution at Time 2, although the value of these information criteria was almost identical for the solutions including three, four, five, and even six profiles at Time 2 . We thus carefully examined the solutions including three to six profiles at both time points. This examination showed that all solutions were fully proper statistically and characterized by a high level of similarity across time points.

Furthermore, this examination revealed that moving from a three-profile solution to a four-profile solution, and then from a four-profile solution to a five-profile solution resulted in the addition of meaningfully different profiles to the solution across time points, whereas moving from a five-profile solution to six- or seven-profile solutions simply resulted in the arbitrary division of one profile into similar profiles. The five-profile solution was thus retained at both time points, supporting its configural similarity.

A longitudinal LPA model of configural similarity including five profiles per time point was then estimated. The fit indices from all longitudinal LPAs are reported in Table 3, and supported the structural, dispersion, and distributional similarity of the profiles across time points as each of these constraints resulted in a decrease in the value of all information criteria. The model of distributional similarity was retained for interpretation and for the next stages of analyses, and is illustrated in Figure 1. The exact within-profile means and variances are reported in Table S7 of the online supplements, while the classification accuracy of participants into their most likely profile at both time points is reported in Table S8 of the online supplements. These results indicate a high classification accuracy, varying from $75.6 \%$ to $88.9 \%$ across profiles at Time 1 , and from $72.9 \%$ to $90.0 \%$ at Time 2 , which is aligned with the high entropy value of .781 associated with this solution.

Profile 1 was characterized by moderately high levels of global work engagement, vigor, and dedication, but very low levels of absorption. This engaged yet distanced profile was the smallest and characterized $3.55 \%$ of the participants. Profile 2 rather seemed to represent a normative profile, representing the majority of the sample $(74.9 \%)$ and characterized by average levels on all indicators (global work engagement, vigor, dedication, and absorption). Profile 3 included participants characterized by moderately low levels of global work engagement, average levels of dedication, and very high levels of vigor and absorption. This vigorously absorbed profile characterized $7.26 \%$ of the participants. Members of Profile 4 were characterized by moderately low levels of global work engagement and absorption, low levels of dedication, and very high levels of vigor. This disengagedvigorous profile characterized $7.24 \%$ of the participants. Profile 5 was characterized by very low levels of global work engagement, and by low to very low levels of vigor, dedication, and absorption. This totally disengaged profile characterized $7.36 \%$ of the participants.

Latent Transitions. As noted above, the final model of distributional similarity was converted to a LTA using the manual auxiliary three-step approach (Asparouhov \& Muthén, 2014; Morin \& Litalien, 2017). The transition probabilities from this LTA are reported in Table 4. These results showed that membership into all profiles was very stable over time, with stability rates varying from $92.6 \%$ to $100 \%$ across profiles. Given this high level of within-person profile stability, transitions were relatively rare. Still, employees initially characterized by a disengaged-vigorous profile (Profile 4 ), when they transitioned to another profile at Time 2 , only did so toward the totally disengaged profile (Profile 5: 7.4\%). In contrast, among employees initially corresponding to the totally disengaged profile (Profile 5), 4.6\% transitioned toward the vigorously absorbed profile (Profile 3) and $2 \%$ transitioned toward the engaged yet distanced profile (Profile 1). Among employees initially corresponding to the vigorously absorbed profile (Profile 3), 4.8\% transitioned toward the normative profile (Profile 2) and 2.2\% transitioned toward the totally disengaged profile (Profile 5).

Predictors of Profile Membership. Demographic predictors were added to this LTA model. As shown in the bottom of Table 3, the null effects model resulted in the lowest values for all information criteria, thus supporting the lack of relations between these demographic controls and the likelihood of membership into the various profiles. Examination of the parameter estimates from these alternative models supported this conclusion regarding the lack of meaningful associations between the controls and the profiles, and the decision to exclude controls from further analyses.

Outcomes of Profile Membership. Outcomes were finally included to this final LTA model. As 
shown in Table 3, the model of explanatory similarity resulted in the lowest values for all information criteria when compared to the alternative models, thus supporting the explanatory similarity of the model. The within-profile means (and 95\% confidence intervals) of each outcome are reported in Table 5. The results revealed a clear differentiation between the profiles that varied depending on the desirability of the outcomes considered. First, when we consider the least desirable outcomes (stress and intentions to quit), the higher levels were observed in Profile 4 (disengaged-vigorous), followed by Profile 5 (totally disengaged), then by Profile 2 (normative), and finally by Profile 1 (engaged yet distanced), with all of these differences being statistically significant. However, although levels of stress and intentions to quit were higher in Profile 3 (vigorously absorbed) than in Profile 1 (engaged yet distanced), differences between Profile 3 and the remaining profiles were not statistically significant. Turning now to the more desirable outcomes (job satisfaction and health), opposite associations were observed, showing that the highest levels were associated with Profile 1 (engaged yet distanced), followed by Profile 2 (normative), then by Profile 3 (vigorously absorbed), then by Profile 5 (totally disengaged), and finally by Profile 4 (disengaged-vigorous). Only one of these differences was non-significant statistically, showing that the levels of health (but not job satisfaction) could not be differentiated across Profiles 5 (totally disengaged) and 3 (vigorously absorbed).

\section{Discussion}

The present study was anchored into a substantive-methodological synergy framework (Marsh \& Hau, 2007). As recently demonstrated by Morin, Boudrias et al. (2017), proper variable- and personcentered methodologies are required to adequately reflect the dimensionality of psychological constructs. This research provided organizational researchers with an illustration of the application of complementary variable- and person-centered approaches designed to achieve a more complete investigation of the dimensionality of psychometric constructs. Through the application of this framework, this study also proposed an improved representation of the underlying structure of employees' work engagement ratings, showed how this improved representation provided a way to identify more clearly differentiated work engagement profiles, and demonstrated the within-person and within-sample stability of these profiles over a four-month period.

\section{A Variable-Centered Perspective}

The application of the variable-centered framework proposed by Morin and colleagues (Morin, Arens, \& Marsh, 2016; Morin, Boudrias et al., 2016, 2017) starts with the comparison of alternative measurement models aiming to assess the presence of construct-relevant multidimensionality due to the assessment of conceptually-related (CFA versus ESEM) and hierarchically-ordered (first-order versus bifactor models) constructs. In the present study, the first of these comparisons supported the superiority of an ESEM (relative to a CFA) representation of employees' work engagement ratings. Indeed, this ESEM solution resulted in a higher level of fit to the data and, most importantly, in more differentiated factors. Given statistical research that has shown ESEM to result in more precise estimates of factor correlations whenever cross-loadings are present in the population model, yet to remain unbiased otherwise (Asparouhov et al., 2015), observing reduced factor correlations represents a strong source of support to the superiority of the ESEM solution (e.g., Perreira et al., 2018). Furthermore, the second of these comparisons supported the superiority of a bifactor-ESEM (relative to a first-order ESEM) representation of participants' answers to the work engagement instrument considered here (UWES-17; Schaufeli et al., 2002).

Theoretical Implications. Taken together, these variable-centered results show that employees' ratings of work engagement simultaneously serve to reflect a global overarching work engagement construct underlying responses to the complete set of items included in this scale, as well as three conceptually-related specific work engagement facets (vigor, dedication, and absorption). This finding thus suggests that the two apparently divergent perspectives exposed in the introduction might in fact be complementary in nature: Work engagement ratings might indeed be driven by a global overarching dimension (Schaufeli et al., 2018; Siu et al., 2014) and this global dimension may co-exist with more specific constructs reflecting employees' level of vigor, dedication, and absorption remaining unexplained by this global work engagement construct (Gillet, Becker et al., 2017; Reis et al., 2017). The bifactor-ESEM framework provides a way to achieve in a single model a natural disaggregation of the effects attributable to global work engagement relative to the three more specific work engagement components (vigor, dedication, and absorption). As noted by Tóth-Király et al. (2018), bifactor-ESEM thus makes it possible for researchers to simultaneously consider both the 
"forest and the trees", or to "have their cake and eat it too". Arguably, the identification of this improved representation of the underlying dimensionality of the work engagement construct represents a key contribution of the present research, and suggests that researchers should at least consider the applicability of this bifactor-ESEM framework as a starting point for their own research.

Practical Implications. In practical terms, these variable-centered results show that it is possible to simultaneously obtain a direct explicit estimate of the extent to which the levels of vigor, dedication, and absorption are balanced for a specific individual (the global component), together with a non-redundant estimate of imbalance in the level of each work engagement component relative to all others for a specific individual (i.e., expressed as deviations from that global level). Importantly, failure to consider the possibility that work engagement ratings may indeed simultaneously tap into two types of latent constructs, one reflecting global balance in work engagement levels and one reflecting specific forms of imbalance in the level of each work engagement component is likely to erroneously lead to the conclusion that vigor, dedication, and absorption reflect relatively independent, albeit complementary, constructs. However, by forcing participants' global levels of work engagement to be directly absorbed into their levels of vigor, dedication, and absorption, research conducted while ignoring this multidimensionality is likely to erroneously conclude that each work engagement component has comparable effects on outcome measures. Yet, these comparable effects would in fact simply serve to reflect the underlying effects of participants' global levels of work engagement balance and serve to hide the possible complementary effects of work engagement imbalance.

Although it is relatively easy to grasp why some specific item ratings might present small crossloadings on secondary factors, it might seem more logical, and parsimonious, to simply ignore these secondary associations. However, statistical research shows that excluding even negligible crossloadings as small as .100 tends to result in inflated estimates of the G-factor in bifactor-CFA and of factor correlations in CFA, whereas unnecessary cross-loadings do not to result in estimation biases (for a review, see Asparouhov et al., 2015). This means that even though these cross-loadings may not be substantively important in their own right, excluding them is likely to result in a biased picture of the way constructs tend to be related with one another (Asparouhov et al., 2015) and with other constructs (Mai, Zhang, \& Wen, 2018). In plain language, failure to take this form of multidimensionality into account is likely to lead to a biased view of the validity of the constructs under consideration. Worse, inflation of factor correlations could also result in multicollinearity (Morin, Marsh, \& Nagengast, 2013), leading to suppression effects and in an erroneous view of the reality under study.

\section{A Person-Centered Perspective}

Many studies have shown that the three dimensions of work engagement (i.e., vigor, dedication, and absorption) are moderately to strongly interrelated (e.g., Gillet et al., 2013). Yet, the added value of considering how these components combine into specific profiles of workers remains understudied (e.g., Simbula et al., 2013). In particular, the true added value of considering each specific work engagement component, once employees' global levels of work engagement are taken into account, remains unknown. The reliance on a person-centered approach appeared to be particularly well suited to these considerations, providing a way to assess how global and specific (vigor, dedication, and absorption) work engagement components are combined among different profiles of employees.

Morin, Boudrias et al. $(2016,2017)$ demonstrated the importance of adopting a proper variablecentered measurement model as a starting point for person-centered analyses. Importantly, they showed that failure to take into account construct-relevant psychometric multidimensionality present in participants' responses could lead to the estimation of latent profiles in which shape differences are minimized and level differences artificially inflated. Based on the observation that a bifactor-ESEM solution best represented participants' ratings of work engagement, Simbula et al.'s (2013) failure to take these two forms of multidimensionality into account might explain why their results simply revealed two profiles presenting almost pure level differences (i.e., characterized by high or moderate levels of work engagement across dimensions). In the present study, work engagement profiles were estimated based on factor scores from the previously described bifactor-ESEM models.

Theoretical Implications. Our person-centered results revealed clear shape differences between profiles. These profiles support the theoretical value of adopting a finer-grained representation of work engagement incorporating both the global quantity of work engagement across all three components, and the specificity associated with each dimension over and above this global level of work 
engagement. More precisely, our results revealed five well-differentiated work engagement profiles: (a) engaged yet distanced (moderately high levels of global work engagement, vigor, and dedication, and very low levels of absorption); (b) normative (average levels on global work engagement, vigor, dedication, and absorption); (c) vigorously absorbed (moderately low levels of global work engagement, average levels of dedication, and very high levels of vigor and absorption); (d) disengaged-vigorous (moderately low levels of global work engagement and absorption, low levels of dedication, and very high levels of vigor); and (e) totally disengaged (very low levels of global work engagement, and low to very low levels of vigor, dedication, and absorption).

The identification of a large (74.9\%) normative profile suggests that, for the majority of the sample, global levels of work engagement remain satisfactory and balanced with the specific components (vigor, dedication, and absorption). This result is aligned with the results from Morin, Boudrias et al. $(2016,2017)$ who also identified the presence of a dominant normative profile characterized by moderate levels of well-being (2017) or psychological health (2016), accompanied by smaller additional profiles. Apart from this normative profile, it is interesting to note that all other profiles are characterized by discrepant levels of work engagement across dimensions, and particularly that three of them (Profiles 3, 4, and 5) described globally disengaged employees.

To better understand the meaning and the psychological processes involved in these more specific profiles, it is helpful to consider their associations with the various outcomes considered in this study. Specifically, the most desirable outcome levels (higher levels of job satisfaction and health as well as lower levels of stress and intentions to quit) were observed in the engaged yet distanced profile (1), followed closely by the normative (2) one. In other words, the two profiles characterized by the highest levels of global work engagement, regardless of their levels on the specific work engagement components (vigor, dedication, and absorption) were found to be associated with the most desirable outcomes. This result suggests that that the key determinant of positive outcomes seems to be the presence of high levels of global work engagement, rather than the levels on any specific work engagement components over and above that global level of work engagement. This conclusion supports Schaufeli and Bakker's (2004) proposition regarding the positive implications of global levels of work engagement, while being aligned with previous results showing that global levels of work engagement were particularly beneficial in terms of outcomes (Siu et al., 2014).

One might wonder about the desirability of the engaged yet distanced profile (characterized by very low specific levels of absorption) relative to the normative profile (characterized by balanced specific levels of vigor, dedication, and absorption) from an outcomes perspective. This observation could be related both to the fact that the engaged yet distanced employees tend to present higher specific levels of vigor and dedication than those corresponding to the normative profile, which would be consistent with the theoretically positive role ascribed to all work engagement components (Demerouti et al., 2010). However, this result also suggests that there might be benefits for highly engaged workers to maintain a healthy distance from their work (i.e., low levels of absorption). There might thus be limits to the benefits associated with very high levels of work engagement, at least for a small subsample of workers (3.55\%). This interpretation is aligned with the possible "dark side" of work engagement alluded to by Sonnentag (2011), and supported by Caesens et al. (2016). Indeed, these authors revealed a curvilinear (inverted U-shape) relation between work engagement and employees' turnover intentions, showing that extreme levels of work engagement ceased to be beneficial in terms of reducing turnover intentions (Caesens et al., 2016). It is interesting to note that this interpretation is also aligned with research on the concept of over-commitment (e.g., Siegrist et al., 2004), showing that whereas employees' commitment tends to be associated with a variety of positive work outcomes (e.g., Meyer, Stanley, Herscovitch, \& Topolnytsky, 2002), extreme levels of commitment appear more problematic (Morin, Vandenberghe, Turmel, Madore, \& Maïano, 2013).

Turning now our attention to the profiles characterized by lower levels of global work engagement, it is highly informative to consider the differences between these three profiles, all associated with less desirable outcomes than the normative and engaged yet distanced profiles, from an outcomes perspective. Thus, although the disengaged-vigorous (4) and totally disengaged (5) profiles are both characterized by moderately low to low levels of dedication and absorption, the disengaged-vigorous profile is characterized by very high levels of vigor and moderately low levels of global work engagement, whereas the totally disengaged profile is characterized by very low levels of vigor and global work engagement. The disengaged-vigorous profile (4) also appears to be the least 
desirable one from an outcomes perspective. This difference suggests that high levels of vigor may amplify the negative effects of a low level of global work engagement. More precisely, it appears to be better for otherwise disengaged workers (low global levels of work engagement), not to spend huge amounts of energy (i.e., vigor) to compensate for their low engagement. Indeed, doing so may contribute to drain their emotional resources, leading to more negative outcomes (Hobfoll, 1989).

The vigorously absorbed profile (3) appears to fall in between the disengaged-vigorous (4) and totally disengaged (5) profiles from an outcomes perspective. Whereas this vigorously absorbed profile (3) presents moderately low global levels of work engagement and high levels of vigor that match the levels observed in the disengaged-vigorous (4) profile, this profile is also characterized by moderately high to high levels of dedication and absorption. The fact that this profile also tends to be associated with worse outcomes than that the totally disengaged (5) profile reinforces our previous interpretation that the combination of low levels of global work engagement and high levels of vigor tends to be problematic. However, the fact that this profile remains slightly more adaptive than the disengaged-vigorous (4) also suggests that when employees are disengaged but spend huge amount of energy at work, having higher levels of absorption and dedication may partly protect them against the depletion of their emotional resources. These results are in line with prior studies showing that vigor tends to be more strongly related to outcomes than dedication and absorption (e.g., Gillet, Becker et al., 2017). These results confirm that specific work engagement components present welldifferentiated relations with outcomes when global levels of work engagement are considered.

In sum, our person-centered results point out the theoretical importance of considering synergistic relations between work engagement components and for the value of jointly considering the global and specific components of work engagement. However, future research should aim to investigate the extent to which the profiles identified here will be replicated in new samples. Future research should also examine how the effects of global work engagement change as a function of the degree of balance between the more specific work engagement components (vigor, dedication, and absorption).

Practical Implications. Several recommendations for practitioners emerge from the present findings. First, our results suggest that managers should be particularly attentive to employees displaying low global levels of work engagement, and especially to those also displaying high levels of vigor (disengaged-vigorous profile) as these workers appeared to be at risk for a variety of work difficulties. In contrast, our results reveal that the two profiles characterized by the highest levels of global work engagement were associated with the most positive outcomes, thus reinforcing the importance of global levels of work engagement. Managers and practitioners should care about the extent to which their employees are characterized by high levels of global work engagement and try to foster these levels. It also appears important to reinforce, among highly engaged employees, the importance of nurturing a healthy level of detachment from their work (lower levels of absorption) given that this combination was found to be associated with the most desirable outcomes in this study.

Knight et al. (2017) recently conducted a systematic review and meta-analysis of the evidence for the effectiveness of controlled work engagement interventions. They identified four types of interventions: (a) Personal resource building interventions, focusing on increasing personal resources (e.g., self-efficacy, optimism); (b) job resource building interventions, focusing on increasing resources in the work environment (e.g., social support); (c) leadership training interventions, involving knowledge and skill building workshops for supervisors; and (d) health promoting interventions, encouraging workers to adopt and sustain healthier lifestyles and to reduce and manage stress. The meta-analytic results demonstrated a significant positive effect of these interventions on work engagement. Furthermore, a moderator analysis did not show a significant effect of intervention type on the effectiveness of work engagement interventions, suggesting that success is not affected by the focus of the intervention. The implementation of such interventions may thus build and sustain employees' levels of work engagement, and increase the relative prevalence of the profiles characterized by the highest levels of work engagement and associated with the most desirable outcomes (engaged yet distanced and normative profiles).

Moreover, in the existing literature, numerous studies demonstrated that transformational leadership behaviors tended to be positively related to work engagement (e.g., Breevaart \& Bakker, 2018; Schmitt, Den Hartog, \& Belschak, 2016). In line with these findings, having supervisors displaying higher levels of transformational leadership behaviors in the workplace could possibly be associated with a greater likelihood of membership into the most desirable profile (engaged yet 
distanced profile). Obviously, future research is needed to ascertain the validity of this suggestion.

\section{A Longitudinal Perspective}

The current study also contributes to the literature by adopting a longitudinal design and addressing the joint issues of within-person and within-sample profile stability (Gillet, Morin, \& Reeve, 2017; Kam et al., 2016). In terms of within-sample stability, the profiles identified in this study were essentially unchanged in terms of number, structure, variability, size, and outcomes across a four-month period, thus supporting their within-sample stability. Our results also showed that membership into the five work engagement profiles remained highly stable across a four-month period (with stability rates ranging from $92.6 \%$ to $100 \%$ ), thus also supporting their within-person stability.

This stability may in part reflect the relatively short time interval considered here (four months versus one-two years). However, the fact that our results also revealed within-person changes suggest that the time interval was sufficient to study changes at the individual level. More importantly, this result reinforces the need for future research to consider the possible mechanisms, especially those that are under organizational control, at play in explaining these profile transitions. Indeed, stability does not mean that profiles are insensitive to management interventions (Kam et al., 2016) but rather indicates that, without intervention, these profiles tend to reflect stable inter-individual differences. In line with recent studies (e.g., Sheng, Wang, Hong, Zhu, \& Zhang, 2018; Sonnentag \& Kühnel, 2016), it would be interesting for further research to disentangle which components of work engagement present the greatest levels of stability or change over time. More importantly, future longitudinal research is needed to address explanations for, and limits to, profile stability while considering longer time periods, different career stages, and employees' possible changes in their personal and professional lives in order to more carefully locate determinants of these changes.

Theoretical Implications. These longitudinal results are in line with those from prior studies showing that work engagement is more strongly related to individual differences than to environmental factors (Bakker, Du, \& Derks, 2018; Kim \& Beehr, 2018). For instance, Salmela-Aro and Upadyaya (2018) showed that the effects of personal resources (resilience) on work engagement were stronger than those of job resources (ability to work, team climate, and role in the organization) in the mid- and late career stages. This was not the case for the employees in the early career stage (employees under age 35 years) with similar or even stronger effects of job resources. These results suggest that the effects of intra-individual and interpersonal factors on work engagement might vary as a function of career stages. It is thus possible that a work engagement profile in which employees in the early career stage are highly represented may be less stable across time (due to a lower influence of personal dimensions) in comparison to a profile mainly characterized by workers in the mid- and late career stages. Future research is needed to test this hypothesis.

Practical Implications. This demonstration of within-sample and within-person profile stability supports the idea that person-centered research on work engagement can be used to guide work engagement interventions (Knight et al., 2017) by showing that these profiles reflect relatively stable inter-individual differences (Kam et al., 2016; Meyer \& Morin, 2016). More precisely, the fact that profiles remained relatively constant should allay fears that work engagement profiles are too ephemeral and responsive to day-to-day fluctuations in working conditions to be of practical value. In contrast, as demonstrated by Strijk, Proper, Van Mechelen, and Van der Beek (2013), it might be interesting to implement a health promoting intervention which has been found to have positive effects on employees' levels of work engagement 12 months later.

\section{Limitations and Directions for Future Research}

The present study has some limitations. First, we used self-report measures that can be impacted by social desirability and self-report biases. We thus encourage researchers to conduct additional research using more objective turnover data as well as informant-reported (e.g., supervisor) measures of creativity and performance as ultimate outcomes. Second, our treatment of some variables as outcomes (i.e., intentions to quit, job satisfaction, health, and stress) was based on theoretical considerations (e.g., Schaufeli \& Bakker, 2004). However, our design did not allow us to rule out the possibility of reverse causality, reciprocal influence, or spurious associations. Future longitudinal research should devote more attention to the identification of the true directionality of the associations among predictors, outcomes, and profiles. It would also be important for future research to better consider the mechanisms involved in both the formation and consequences of work engagement profiles. Third, the time interval between the two measurement waves was relatively short (four 
months), suggesting that the stability of the work engagement profiles could be attenuated over a longer time period. The present study thus suggests that a four-month period might not be a sufficient time interval to a full consideration of stability and change in profile membership, while still suggesting that at least some levels of within-person changes do occur over such a short period. Future research is clearly needed on this issue.

Fourth, we only considered demographic covariables as possible controlled variables in the prediction of work engagement profiles. It would be interesting for future research to consider a more diversified set of determinants of changes in work engagement profiles (e.g., proactive personality, job crafting, organizational culture, transformational leadership). Fifth, it is important to keep in mind that the composite reliability of the absorption S-factor was low. Although it remained important to account for the specificity associated with this S-factor in our models, and although we relied on factors scores incorporating a degree of correction for this measurement error, this result shows that limited level of specific variance remained associated with absorption ratings once global levels of work engagement were taken into account. Future research would be needed to document whether this result is sample specific, or intimately related to the nature of absorption ratings. Finally, our reliance on a convenience sample makes it hard to assess the extent to which this sample can be considered to be representative of the more general populations of workers. A key aspect of the process of construct validation that is required to ascertain that profiles represent substantively meaningful subpopulations is the assessment of the extent to which these profiles generalize to distinct groups of participants (Meyer \& Morin, 2016). More precisely, observing similarity means that generic interventions strategies can be developed and expected to generalize to different types of workers, which is a much more parsimonious approach than having to develop strategies targeting different types of profiles for distinct types of workers. More research is thus needed to obtain a clearer picture of the specific work engagement profiles most frequently occurring in more diversified (in terms of cultures, languages, and professions) and representative samples.

\section{Conclusion}

This study represents an important first step in the investigation of work engagement profiles taking into account the multidimensionality of this construct. More specifically, we first demonstrated the superiority of a bifactor-ESEM representation of employees' ratings of work engagement, showing these ratings to simultaneously tap into two types of latent constructs: (a) one reflecting global balance in work engagement levels, and (2) one reflecting specific forms of imbalance in the level of each work engagement component. Then, relying on factor scores reflecting these two distinct types of constructs, person-centered analyses revealed five distinct and very stable profiles of employees. The two profiles with the lowest levels of global work engagement were associated with the most detrimental outcomes, whereas the most desirable outcomes were associated with the engaged yet distanced profile, followed closely by the normative profile. Further research will be needed to more carefully understand the mechanisms involved in the formation and modification of these profiles, as well as their generalizability to even more diversified samples of employees.

\section{References}

Alessandri, G., Consiglio, C., Borgogni, L., Caprara, G. V., \& Schaufeli, W. B. (2015). From positive orientation to job performance: The role of work engagement and self-efficacy beliefs. Journal of Happiness Studies, 16, 767-788.

Asparouhov, T., \& Muthén, B. O. (2009). Exploratory structural equation modeling. Structural Equation Modeling, 16, 397-438.

Asparouhov, T., \& Muthén, B. O. (2014). Auxiliary variables in mixture modeling: Three-step approaches using Mplus. Structural Equation Modeling, 21, 1-13.

Asparouhov, T., Muthén, B., \& Morin, A. J. S. (2015). Bayesian structural equation modeling with crossloadings and residual covariances. Journal of Management, 41, 1561-1577.

Bakker, A. B. (2014). Daily fluctuations in work engagement: An overview and current directions. European Psychologist, 19, 227-236.

Bakker, A. B., Du, D., \& Derks, D. (2018). Major life events in family life, work engagement, and performance: A test of the work-home resources model. International Journal of Stress Management. doi: 10.1037/str0000108

Bal, P. M., \& De Lange, A. H. (2015). From flexibility human resource management to employee engagement and perceived job performance across the lifespan: A multisample study. Journal of 
Occupational and Organizational Psychology, 88, 126-154.

Bauer, D. J., \& Curran, P. J. (2003). Distributional assumptions of growth mixture models overextraction of latent trajectory classes. Psychological Methods, 8, 338-363.

Breevaart, K., \& Bakker, A. B. (2018). Daily job demands and employee work engagement: The role of daily transformational leadership behavior. Journal of Occupational Health Psychology. Advance online publication. doi: 10.1037/ocp0000082

Browne, M. W. (2001). An overview of analytic rotation in exploratory factor analysis. Multivariate Behavioral Research, 36, 111-150.

Brunner, M., Nagy, G., \& Wilhelm, O. (2012). A tutorial on hierarchically structured constructs. Journal of Personality, 80, 796-846.

Caesens, G., Stinglhamber, F., \& Marmier, V. (2016). The curvilinear effect of work engagement on employees' turnover intentions. International Journal of Psychology, 51, 150-155.

Camgoz, S. M., Ekmekci, O., Karapinar, P., \& Guler, B. (2016). Job insecurity and turnover intentions: Gender differences and the mediating role of work engagement. Sex Roles, 75, 583-598.

Chen, F. F. (2007). Sensitivity of goodness of fit indexes to lack of measurement. Structural Equation Modeling, 14, 464-504.

Chen, F., Bollen, K., Paxton, P., Curran, P., \& Kirby, J. (2001). Improper solutions in structural question models. Sociological Methods \& Research, 29, 468-508.

Chen, F. F., West, S. G., \& Sousa, K. H. (2006). A comparison of bifactor and second-order models of quality of life. Multivariate Behavioral Research, 41, 189-225.

Cheung, G. W., \& Rensvold, R. B. (2002). Evaluating goodness-of fit indexes for testing measurement invariance. Structural Equation Modeling, 9, 233-255.

Coetsier, P., De Backer, G., De Corte, W., Helleman, C., Karnas, G., Kornitzer, M., Pelfrène, E., Stam, M., Vlerick, P. (1996). Etude belge du stress au travail: Aperçu du modèle de recherche et des outils d'investigation [Belgian study of work stress: Outline of research model and research tools]. Psychologie \& Psychométrie, 17, 17-35.

Collins, L. M., \& Lanza, S. T. (2010). Latent class and latent transition analysis: With applications in the social, behavioral, and health sciences. New York, NY: Wiley.

Costa, P. L., Passos, A. M., \& Bakker, A. B. (2014). Team work engagement: A model of emergence. Journal of Organizational and Occupational Psychology, 87, 414-436.

Demerouti, E., Mostert, K., \& Bakker, A. B. (2010). Burnout and work engagement: A thorough investigation of the independency of both constructs. Journal of Occupational Health Psychology, 15, 209-222.

Diallo, T. M. O, Morin, A. J. S., \& Lu, H. (2016). Impact of misspecifications of the latent variancecovariance and residual matrices on the class enumeration accuracy of growth mixture models. Structural Equation Modeling, 23, 507-531.

Diallo, T. M. O., Morin, A. J. S., \& Lu, H. (2017). The impact of total and partial inclusion or exclusion of active and inactive time invariant covariates in growth mixture models. Psychological Methods, 22, 166-190.

Eisenberger, R., Cummings, J., Armeli, S., \& Lynch, P. (1997). Perceived organizational support, discretionary treatment, and job satisfaction. Journal of Applied Psychology, 82, 812-820.

Enders, C. K. (2010). Applied missing data analysis. New York, NY: Guilford.

Engelbrecht, A. S., Heine, G., \& Mahembe, B. (2017). Integrity, ethical leadership, trust and work engagement. Leadership \& Organization Development Journal, 38, 368-379.

Ettner, S. L., (1996). New evidence on the relationship between income and health. Journal of Health Economics, 15, 67-85.

Finney, S. J., \& DiStefano, C. (2013). Non-normal and categorical data in structural equation modeling. In G. R. Hancock \& R. O. Mueller (Eds.), Structural equation modeling: A second course $\left(2^{\text {nd }}\right.$ ed., pp. 439-492). Charlotte, NC: Information Age.

Fredrickson, B. L. (2001). The role of positive emotions in positive psychology: The broaden-and-build theory of positive emotions. American Psychologist, 56, 218-226.

Gignac, G. E. (2016). The higher-order model imposes a proportionality constraint: That is why the bifactor model tends to fit better. Intelligence, 55, 57-68.

Gillet, N., Becker, C., Lafrenière, M.-A. K., Huart, I., \& Fouquereau, E. (2017). Organizational support, job resources, soldiers' motivational profiles, work engagement, and affect. Military 
Psychology, 29, 418-433.

Gillet, N., Huart, I., Colombat, P., \& Fouquereau, E. (2013). Perceived organizational support, motivation, and engagement among police officers. Professional Psychology: Research and Practice, 44, 46-55.

Gillet, N., Morin, A. J. S., \& Reeve, J. (2017). Stability, change, and implications of students' motivation profiles: A latent transition analysis. Contemporary Educational Psychology, 51, 222-239.

Graham, J. W. (2009). Missing data analysis. Annual Review of Psychology, 60, 549-576.

Hakanen, J. J., Peeters, M. C. W., \& Schaufeli, W. B. (2018). Different types of employee well-being across time and their relationships with job crafting. Journal of Occupational Health Psychology. Advance online publication. doi: 10.1037/ocp0000081

Halbesleben, J. R. B. (2010). A meta-analysis of work engagement: Relationships with burnout, demands, resources, and consequences. In A. B. Bakker \& M. P. Leiter (Eds.), Work engagement: A handbook of essential theory and research (pp. 102-117). New York, NY: Psychology Press.

Henson, J. M., Reise, S. P., \& Kim, K. H. (2007). Detecting mixtures from structural model differences using latent variable mixture modeling. Structural Equation Modeling, 14, 202-226.

Hipp, J. R., \& Bauer, D. J. (2006). Local solutions in the estimation of growth mixture models. Psychological Methods, 11, 36-53.

Hobfoll, S. E. (1989). Conservation of resources: A new attempt at conceptualizing stress. American Psychologist, 44, 513-524.

Hu, L.-T., \& Bentler, P. M. (1999). Cutoff criteria for fit indexes in covariance structure analysis: Conventional criteria versus new alternatives. Structural Equation Modeling, 6, 1-55.

Huyghebaert, T., Gillet, N., Fernet, C., Lahiani, F.-J., Chevalier, S., \& Fouquereau, E. (2018). Investigating the longitudinal effects of surface acting on managers' functioning through psychological needs. Journal of Occupational Health Psychology, 23, 207-222.

Innanen, H., Tolvanen, A., \& Salmela-Aro, K. (2014). Burnout, work engagement and workaholism among highly educated employees. Burnout Research, 1, 38-49.

Jaros, S. (1997). An assessment of Meyer and Allen's (1991) three-component model of organizational commitment and turnover intentions. Journal of Vocational Behavior, 51, 319-337.

Jeličič, H., Phelps, E., \& Lerner, R. M. (2009). Missing data methods in longitudinal studies: The persistence of bad practices. Developmental Psychology, 45, 1195-1199.

Kam, C., Morin, A. J. S., Meyer, J. P., \& Topolnytsky, L. (2016). Are commitment profiles stable and predictable? A latent transition analysis. Journal of Management, 42, 1462-1490.

Kim, M., \& Beehr, T. A. (2018). Challenge and hindrance demands lead to employees' health and behaviours through intrinsic motivation. Stress and Health. Advance online publication. doi: 10.1002/smi.2796

Knight, C., Patterson, M., \& Dawson, J. F. (2017). Building work engagement: A systematic review and meta-analysis investigating the effectiveness of work engagement interventions. Journal of Organizational Behavior, 38, 792-812.

Kühnel, J., Sonnentag, S., \& Bledow, R. (2012). Resources and time pressure as day-level antecedents of work engagement. Journal of Occupational and Organizational Psychology, 85, 181-198.

Larsen, R. (2011). Missing data imputation versus full information maximum likelihood with second level dependencies. Structural Equation Modeling, 18, 649-662.

Lesener, T., Gusy, B., \& Wolter, C. (2018). The job demands-resources model: A meta-analytic review of longitudinal studies. Work \& Stress. Advance online publication. doi: 10.1080/02678373.2018.1529065

Little, T. D., Lindenberger, U., \& Nesselroade, J. R. (1999). On selecting indicators for multivariate measurement and modeling with latent variables: When "good" indicators are bad and "bad" indicators are good. Psychological Methods, 4, 192-211.

Lo, Y., Mendell, N. R., \& Rubin, D. B. (2001). Testing the number of components in a normal mixture. Biometrika, 88, 767-778.

Lubke, G., \& Muthén, B. O. (2007). Performance of factor mixture models as a function of model size, covariate effects, and class-specific parameters. Structural Equation Modeling, 14, 26-47.

Mai, Y., Zhang, Z., \& Wen, Z. (2018). Comparing exploratory structural equation modeling and existing approaches for multiple regression with latent variables. Structural Equation Modeling. Advance online publication. doi: 10.1080/10705511.2018.1444993 
Mäkikangas, A., Feldt, T., Kinnunen, U., \& Tolvanen, A. (2012). Do low burnout and high work engagement always go hand in hand? Investigation of the energy and identification dimensions in longitudinal data. Anxiety, Stress \& Coping: An International Journal, 25, 93-116.

Mäkikangas, A., Hyvönen, K., \& Feldt, T. (2017). The energy and identification continua of burnout and work engagement: Developmental profiles over eight years. Burnout Research, 5, 44-54.

Mäkikangas, A., \& Kinnunen, U. (2016). The person-oriented approach to burnout: A systematic review. Burnout Research, 3, 11-23.

Mäkikangas, A., Kinnunen, U., Feldt, T., \& Schaufeli, W. B. (2016). The longitudinal development of employee well-being: A systematic review. Work \& Stress, 30, 46-70.

Mäkikangas, A., Rantanen, J., Bakker, A. B., Kinnunen, M.-L., Pulkkinen, L., \& Kokko, K. (2015). The circumplex model of occupational well-being: Its relation with personality. Journal for Person-Oriented Research, 1, 115-129.

Mäkikangas, A., Schaufeli, W., Tolvanen, A., \& Feldt, T. (2013). Engaged managers are not workaholics: Evidence from a longitudinal person-centered analysis. Revista de Psicología del Trabajo y de las Organizaciones, 29, 135-143.

Marsh, H. W. (2007). Application of confirmatory factor analysis and structural equation modeling in sport/exercise psychology. In G. Tenenbaum \& R.C. Eklund (Eds.), Handbook of sport psychology $\left(3^{\text {rd }}\right.$ ed., pp. 774-798). New York, NY: Wiley.

Marsh, H. W., \& Hau, K. T. (2007). Applications of latent-variable models in psychology: The need for methodological-substantive synergies. Contemporary Educational Psychology, 32, 151-170.

Marsh, H. W., Hau, K. T., \& Grayson, D. (2005). Goodness of fit evaluation in structural equation modeling. In A. Maydeu-Olivares \& J. McArdle (Eds.), Contemporary psychometrics (pp. 275-340). Mahwah, NJ: Erlbaum.

Marsh, H. W., Hau, K. T., \& Wen, Z. (2004). In search of golden rules: Comment on hypothesis-testing approaches to cutoff values for fit indexes and dangers in overgeneralizing Hu \& Bentler's (1999) findings. Structural Equation Modeling, 11, 320-341.

Marsh, H. W., Lüdtke, O., Trautwein, U., \& Morin, A. J. S. (2009). Classical latent profile analysis of academic self-concept dimensions: Synergy of person- and variable-centered approaches to theoretical models of self-concept. Structural Equation Modeling, 16, 191-225.

Marsh, H. W., Morin, A. J. S., Parker, P. D., \& Kaur, G. (2014). Exploratory structural equation modelling: An integration of the best features of exploratory and confirmatory factor analyses. Annual Review of Clinical Psychology, 10, 85-110.

McDonald, R. P. (1970). Theoretical foundations of principal factor analysis, canonical factor analysis, and alpha factor analysis. British Journal of Mathematical \& Statistical Psychology, 23, 1-21.

McLachlan, G., \& Peel, D. (2000). Finite mixture models. New York, NY: Wiley.

Meyer, J. P., \& Morin, A. J. S. (2016). A person-centered approach to commitment research: Theory, research, and methodology. Journal of Organizational Behavior, 37, 584-612.

Meyer, J. P., Stanley, D .J., Herscovitch, L., \& Topolnytsky, L. (2002). Affective, continuance and normative commitment to the organization: A meta-analysis of antecedents, correlates, and consequences. Journal of Vocational Behavior, 61, 20-52.

Millsap, R. (2011). Statistical approaches to measurement invariance. New York, NY: Taylor \& Francis.

Morin, A. J. S. (2016). Person-centered research strategies in commitment research. In J. P. Meyer (Ed.), The handbook of employee commitment (pp. 490-508). Cheltenham, UK: Edward Elgar.

Morin, A. J. S., Arens, A., \& Marsh, H. (2016). A bifactor exploratory structural equation modeling framework for the identification of distinct sources of construct-relevant psychometric multidimensionality. Structural Equation Modeling, 23, 116-139.

Morin, A. J. S., Arens, A., Tran, A., \& Caci, H. (2016). Exploring sources of construct-relevant multidimensionality in psychiatric measurement: A tutorial and illustration using the Composite Scale of Morningness. International Journal of Methods in Psychiatric Research, 25, 277-288.

Morin, A. J. S., Boudrias, J.-S., Marsh, H. W., Madore, I., \& Desrumaux, P. (2016). Further reflections on disentangling shape and level effects in person-centered analyses: An illustration aimed at exploring the dimensionality of psychological health. Structural Equation Modeling, 23, 438-454.

Morin, A. J. S., Boudrias, J.-S., Marsh, H. W., McInerney, D. M., Dagenais-Desmarais, V., Madore, I., \& Litalien, D. (2017). Complementary variable- and person-centered approaches to exploring the dimensionality of psychometric constructs: Application to psychological wellbeing at work. 
Journal of Business and Psychology, 32, 395-419.

Morin, A. J. S., \& Litalien, D. (2017). Webnote: Longitudinal tests of profile similarity and latent transition analyses. Montreal, Canada: Substantive Methodological Synergy Research Laboratory. http://smslabstats.weebly.com/uploads/1/0/0/6/100647486/lta_distributional_similarity_v02.pdf

Morin, A. J. S., Maïano, C., Nagengast, B., Marsh, H. W., Morizot, J., \& Janosz, M. (2011). Growth mixture modeling of adolescents trajectories of anxiety: The impact of untested invariance assumptions on substantive interpretations. Structural Equation Modeling, 18, 613-648.

Morin, A. J. S., \& Marsh, H. W. (2015). Disentangling shape from levels effects in person-centered analyses: An illustration based on University teacher multidimensional profiles of effectiveness. Structural Equation Modeling, 22, 39-59.

Morin, A. J. S., Marsh, H. W., \& Nagengast, B. (2013). Exploratory structural equation modeling. In G. R. Hancock \& R. O. Mueller (Eds.), Structural equation modeling: A second course ( $2^{\text {nd }}$ ed., pp. 395-436). Charlotte, NC: Information Age.

Morin, A. J. S., Meyer, J. P., Creusier, J., \& Biétry, F. (2016). Multiple-group analysis of similarity in latent profile solutions. Organizational Research Methods, 19, 231-254.

Morin, A. J .S., Vandenberghe, C., Turmel, M., Madore, I., \& Maïano, C. (2013). Probing into commitment's nonlinear relationships to work outcomes. Journal of Managerial Psychology, 28, 202-223.

Morin, A. J. S., \& Wang, J. C. K. (2016). A gentle introduction to mixture modeling using physical fitness data. In N. Ntoumanis \& N. Myers (Eds.), An introduction to intermediate and advanced statistical analyses for sport and exercise scientists (pp. 183-210). London, UK: Wiley.

Murray, A., \& Johnson, W. (2013). The limitations of model fit in comparing the bifactor versus higherorder models of cognitive ability structure. Intelligence, 41, 407-422.

Muthén, L. K., \& Muthén, B. (2017). Mplus user's guide. Los Angeles, CA: Muthén \& Muthén.

Muthén, B. O. (2003). Statistical and substantive checking in growth mixture modeling: Comment on Bauer and Curran (2003). Psychological Methods, 8, 369-377.

Nunnally, J., \& Bernstein, I. (1994). Psychometric theory, $3^{\text {rd }}$ ed. New York, NY: McGraw-Hill.

Nylund, K. L., Asparouhov, T., \& Muthén, B. (2007). Deciding on the number of classes in latent class analysis and growth mixture modeling: A Monte Carlo simulation study. Structural Equation Modeling, 14, 535-569.

Pelfrene E., Vlerick, P., Kittel F., Mak R. P., Kornitzer, M., \& De Backer, G. (2002). Psychosocial work environment and psychological well-being: Assessment of the buffering effects in the job demand-control(-support) model in Belstress. Stress and Health, 18, 43-56.

Perera, H. N., Vosicka, L., Granziera, H., \& Mcllveen, P. (2018). Towards an integrative perspective on the structure of teacher work engagement. Journal of Vocational Behavior, 108, 28-41.

Perreira, T. A., Morin, A. J. S., Hebert, M., Gillet, N., Houle, S. A., \& Berta, W. (2018). The short form of the Workplace Affective Commitment Multidimensional Questionnaire (WACMQ-S): A bifactorESEM approach among healthcare professionals. Journal of Vocational Behavior, 106, 62-83.

Peugh, J., \& Fan, X. (2013). Modeling unobserved heterogeneity using latent profile analysis: A Monte Carlo simulation. Structural Equation Modeling, 20, 616-639.

Raykov, T., \& Marcoulides, G. A. (2004). Using the delta method for approximate interval estimation of parameter functions in SEM. Structural Equation Modeling, 11, 621-637.

Reis, D., Hoppe, A., Arndt, C., \& Lischetzke, T. (2017). Time pressure with state vigour and state absorption. European Journal of Work and Organizational Psychology, 26, 94-106.

Reise, S. P. (2012). The rediscovery of bifactor measurement models. Multivariate Behavioral Research, 47, 667-696.

Reise, S. P., Moore, T. M., \& Maydeu-Olivares, A. (2011). Targeted bifactor rotations and assessing the impact of model violations on the parameters of unidimensional and bifactor models. Educational and Psychological Measurement, 71, 684-711.

Rindskopf, D., \& Rose, T. (1988). Some theory and applications of confirmatory second-order factor analysis. Multivariate Behavioral Research, 23, 51-67.

Rudolph, C. W., \& Baltes, B. B. (2017). Age and health jointly moderate the influence of flexible work arrangements on work engagement: Evidence from two empirical studies. Journal of Occupational Health Psychology, 22, 40-58.

Salmela-Aro, K., \& Upadyaya, K. (2018). Role of demands-resources in work engagement and burnout in different career stages. Journal of Vocational Behavior, 108, 190-200. 
Saunders, P. (1996). Income, health and happiness. The Australian Economic Review, 29, 353-366.

Schaufeli, W. B., \& Bakker, A. (2004). Job demands, job resources, and their relationship with burnout and engagement: A multi-sample study. Journal of Organizational Behavior, 25, 293-315.

Schaufeli, W. B., Bakker, A., \& Salanova, M. (2006). The measurement of work engagement with a short questionnaire: A cross-national study. Educational \& Psychological Measurement, 66, 701-716.

Schaufeli, W. B., Salanova, M., Gonzalez-Roma, V., \& Bakker, A. (2002). The measurement of burnout and engagement: A confirmatory factor analytic approach. Journal of Happiness Studies, 3, 71-92.

Schaufeli, W. B., Shimazu, A., Hakanen, J., Salanova, M., \& De Witte, H. (2018). An ultra-short measure for work engagement: The UWES-3 validation across five countries. European Journal of Psychological Assessment. Advance online publication. doi: 10.1027/1015-5759/a000430

Schmitt, A., Den Hartog, D. N., \& Belschak, F. D. (2016). Transformational leadership and proactive work behaviour: A moderated mediation model including work engagement and job strain. Journal of Occupational and Organizational Psychology, 89, 588-610.

Seppälä, P., Hakanen, J., Mauno, S., Perhoniemi, R., Tolvanen, A., \& Schaufeli, W. (2015). Stability and change model of job resources and work engagement: A seven-year three-wave follow-up study. European Journal of Work and Organizational Psychology, 24, 360-375.

Sheng, X., Wang, Y., Hong, W., Zhu, Z., \& Zhang, X. (2018). The curvilinear relationship between daily time pressure and work engagement: The role of psychological capital and sleep. International Journal of Stress Management. Advance online publication. doi: 10.1037/str0000085

Siegrist, J., Starke, D., Chandola, T., Godin, I., Marmot, M., Niedhammer, I., \& Peter, R. (2004). The measurement of effort-reward imbalance at work: European comparisons. Social Science \& Medicine, 58, 1483-1499.

Simbula, S., Guglielmi, D., Schaufeli, W. B., \& Depolo, M. (2013). An Italian validation of the Utrecht Work Engagement Scale: Characterization of engaged groups in a sample of schoolteachers. Bollettino Di Psicologia Applicata, 268, 43-54.

Siu, O. L., Bakker, A., \& Jiang, X. (2014). Psychological capital among university students: Relationships with study engagement and intrinsic motivation. Journal of Happiness Studies, 15, 979-994.

Skrondal, A., \& Laake, P. (2001). Regression among factor scores. Psychometrika, 66, 563-576.

Sonnentag, S. (2011). Research on work engagement is well and alive. European Journal of Work and Organizational Psychology, 20, 29-38.

Sonnentag, S., \& Kühnel, J. (2016). Coming back to work in the morning: Psychological detachment and reattachment as predictors of engagement. Journal of Occupational Health Psychology, 21, 379-390.

Steffens, N. K., Yang, J., Jetten, J., Haslam, S. A., \& Lipponen, J. (2017). The unfolding impact of leader identity entrepreneurship on burnout, work engagement, and turnover intentions. Journal of Occupational Health Psychology. Advance online publication. doi: 10.1037/ocp0000090

Streiner, D. L. (2003). Starting at the beginning: An introduction to coefficient alpha and internal consistency. Journal of Personality Assessment, 80, 99-103.

Strijk, J. E., Proper, K. I., Van Mechelen, W., \& Van der Beek, A. J. (2013). Effectiveness of a worksite lifestyle intervention on vitality, work engagement, productivity, and sick leave: Results of a randomized controlled trial. Scandinavian Journal of Work, Environment and Health, 39, 66-75.

Tein, J.-Y., Coxe, S., \& Cham, H. (2013). Statistical power to detect the correct number of classes in latent profile analysis. Structural Equation Modeling, 20, 640-657.

Tofighi, D., \& Enders, C. (2008). Identifying the correct number of classes in growth mixture models. In G. R. Hancock \& K. M. Samuelsen (Eds.), Advances in latent variable mixture models (pp. 317-341). Charlotte, NC: Information Age.

Tóth-Király, I., Morin, A. J. S., Bőthe, B., Orosz, G., \& Rigó, A. (2018). Investigating the multidimensionality of need fulfillment: A bifactor exploratory structural equation modeling representation. Structural Equation Modeling, 25, 267-286.

Warr, P., \& Inceoglu, I. (2017). Work orientations, well-being and job content of self-employed and employed professionals. Work, Employment and Society, 32, 292-311. 


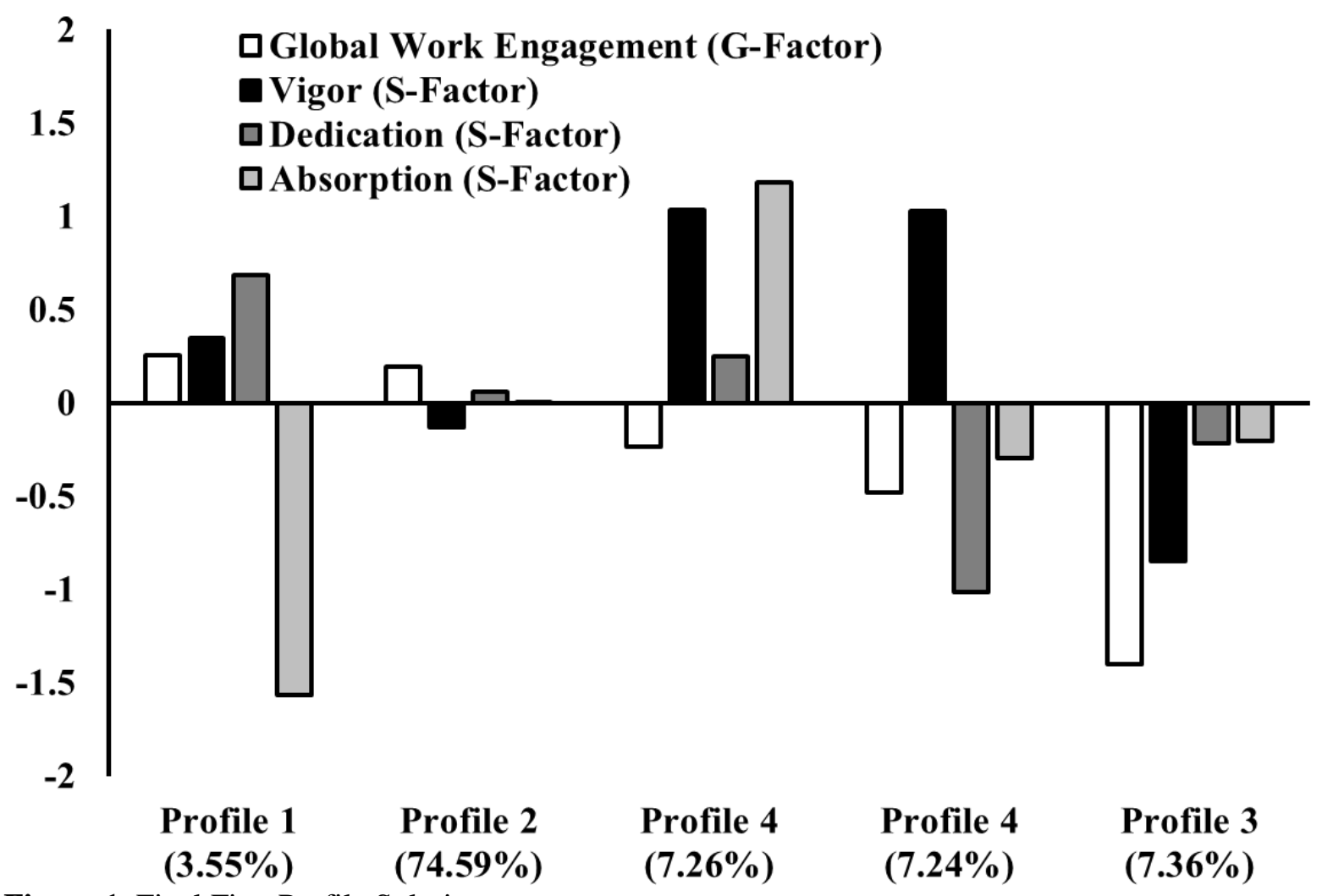

Figure 1. Final Five-Profile Solution

Note. Profile 1: engaged yet distanced profile; Profile 2: normative profile; Profile 3: vigorously absorbed profile; Profile 4: disengaged-vigorous profile; and Profile 5: totally disengaged profile. 
Table 1

Goodness-of-Fit Statistics and Information Criteria for the Work Engagement Measurement Models.

\begin{tabular}{|c|c|c|c|c|c|c|c|c|c|c|}
\hline \multirow{2}{*}{\multicolumn{11}{|c|}{$\begin{array}{l}\text { Model } \\
\text { Work Engagement: Time } 1\end{array}$}} \\
\hline & & & & & & & & & & \\
\hline CFA Time 1 & $661.89 *$ & 116 & .904 & .887 & .083 & {$[.077 ; .089]$} & & & & \\
\hline Bifactor CFA Time 1 & $485.478^{*}$ & 102 & .933 & .910 & .074 & {$[.093 ; .080]$} & & & & \\
\hline ESEM Time 1 & $298.965^{*}$ & 88 & .963 & .943 & .059 & {$[.052 ; .066]$} & & & & \\
\hline Bifactor ESEM Time 1 & $207.261 *$ & 74 & .977 & .957 & .051 & {$[.043 ; .059]$} & & & & \\
\hline \multicolumn{11}{|l|}{ Work Engagement: Time 2} \\
\hline CFA Time 2 & $682.105^{*}$ & 116 & .881 & .860 & .096 & {$[.089 ; .103]$} & & & & \\
\hline Bifactor CFA Time 2 & $480.753^{*}$ & 102 & .920 & .894 & .084 & {$[.077 ; .092]$} & & & & \\
\hline ESEM Time 2 & $359.649 *$ & 88 & .943 & .912 & .077 & {$[.069 ; .085]$} & & & & \\
\hline Bifactor ESEM Time 2 & $221.194 *$ & 74 & .969 & .943 & .062 & {$[.052 ; .071]$} & & & & \\
\hline \multicolumn{11}{|c|}{ Work Engagement: Longitudinal Invariance } \\
\hline M1. Configural invariance & $742.113^{*}$ & 404 & .974 & .963 & .034 & {$[.030 ; .038]$} & - & - & - & - \\
\hline M2. Weak invariance & $776.235^{*}$ & 456 & .975 & .969 & .031 & {$[.027 ; .035]$} & $44.691(52)$ & +.001 & +.006 & -.003 \\
\hline M3. Strong invariance & $795.780 *$ & 469 & .975 & .970 & .031 & {$[.027 ; .035]$} & $18.839(13)$ & .000 & +.001 & .000 \\
\hline M4. Strict invariance & $803.446 *$ & 486 & .975 & .972 & .030 & {$[.026 ; .034]$} & $14.940(17)$ & .000 & +.002 & -.001 \\
\hline M5. Var-Cov invariance & $822.604 *$ & 496 & .975 & .971 & .030 & {$[.026 ; .034]$} & $19.086(10)$ & .000 & -.001 & .000 \\
\hline M6. Latent means invariance & $830.557 *$ & 500 & .974 & .971 & .030 & {$[.026 ; .034]$} & $8.838(4)$ & -.000 & .000 & .000 \\
\hline
\end{tabular}

Note. $* p<.01$; df: Degrees of freedom; CFI: Comparative fit index; TLI: Tucker-Lewis index; RMSEA: Root mean square error of approximation; CI $=$ Confidence interval; $\Delta$ : Change in fit relative to the preceding model in the sequence. 
Table 2

Standardized Factor Loadings $(\lambda)$ and Uniquenesses $(\delta)$ for the Bifactor CFA and ESEM Solutions at Time 1 and 2

\begin{tabular}{|c|c|c|c|c|c|c|c|c|c|c|c|c|c|c|c|c|}
\hline \multirow[b]{2}{*}{ Items } & \multicolumn{3}{|c|}{ Bifactor-CFA Time 1} & \multicolumn{3}{|c|}{ Bifactor-CFA Time 2} & \multicolumn{3}{|c|}{ Bifactor-ESEM Time 1} & \multicolumn{7}{|c|}{ Bifactor-ESEM Time 2} \\
\hline & $\mathrm{G}-\lambda$ & $S-\lambda$ & $\delta$ & $\mathrm{G}-\lambda$ & $S-\lambda$ & $\delta$ & $\mathrm{G}-\lambda$ & $S-\lambda$ & $S-\lambda$ & $S-\lambda$ & $\delta$ & $\mathrm{G}-\lambda$ & $S-\lambda$ & $S-\lambda$ & $S-\lambda$ & $\delta$ \\
\hline Vigor 1 & $.796 * *$ & -.161 & $.340 * *$ & $.791 * *$ & $-.258 * *$ & $.307 * *$ & $.805 * *$ & $-.241 * *$ & $-.148 * *$ & -.056 & $.269 * *$ & $.761 * *$ & $.370 * *$ & -.024 & -.021 & $.283 * *$ \\
\hline Vigor 2 & $.869 * *$ & -.110 & $.233 * *$ & $.870 * *$ & -.152 & $.219 * *$ & $.774 * *$ & $-.171 * *$ & $-.127 * *$ & $-.101 * *$ & $.282 * *$ & $.825 * *$ & $.290 * *$ & -.032 & -.027 & $.123 * *$ \\
\hline Vigor 3 & $.767 * *$ & $-.124 * *$ & $.397 * *$ & $.773 * *$ & $-.255 * *$ & $.338 * *$ & $.790 * *$ & $-.137 * *$ & $.135^{* *}$ & $-.088 *$ & $.362 * *$ & $.772 * *$ & $.296 * *$ & .072 & $-.090 *$ & $.360 * *$ \\
\hline Vigor 4 & $.615 * *$ & $.424 * *$ & $.442 * *$ & $.712 * *$ & $.309 * *$ & $.398 * *$ & $\mathbf{8 8 0} * *$ & $.523 * *$ & $-.112 *$ & .057 & $.170 * *$ & $.849 * *$ & $-.236 * *$ & -.066 & $.091 *$ & $.194 * *$ \\
\hline Vigor 5 & $.542 * *$ & $.400 * *$ & $.546 * *$ & $.615 * *$ & $.388 * *$ & $.472 * *$ & $.856 * *$ & $.263 * *$ & $-.115 * *$ & .055 & $.199 * *$ & $.864 * *$ & $-.196 *$ & -.077 & -.027 & $.187 * *$ \\
\hline Vigor 6 & $.502 * *$ & $.466 * *$ & $.530 * *$ & $.582 * *$ & $.451 * *$ & $.458 * *$ & $.636 * *$ & $.332 * *$ & -.029 & -.030 & $.521 * *$ & $.689 * *$ & $-.212 * *$ & .020 & .021 & $.410 * *$ \\
\hline$\omega$ & & .533 & & & .600 & & & .606 & & & & & .622 & & & \\
\hline Dedication 1 & $.797 * *$ & $.391 * *$ & $.212 * *$ & $.777 * *$ & $.445 * *$ & $.199 * *$ & $.821 * *$ & $-.131 * *$ & $.340 * *$ & -.002 & $.176^{* *}$ & $.823 * *$ & $.126 * *$ & $.397 * *$ & .044 & $.131 * *$ \\
\hline Dedication 2 & $.858 * *$ & $.254 * *$ & $.200 * *$ & $.879 * *$ & $.177 * *$ & $.196 * *$ & $.746 * *$ & $-.115 * *$ & $.233 * *$ & -.012 & $.399 * *$ & $.738 * *$ & $.175^{* *}$ & $.185 * *$ & -.045 & $.354 * *$ \\
\hline Dedication 3 & $.819 * *$ & $.378 * *$ & $.186^{* *}$ & $.844 * *$ & $.356^{* *}$ & $.162 * *$ & $.767 * *$ & $-.124 * *$ & $.368 * *$ & .010 & $.409 * *$ & $.793 * *$ & $.220 * *$ & $.376 * *$ & .043 & $.353 * *$ \\
\hline Dedication 4 & $.767 * *$ & $.285^{* *}$ & $.330 * *$ & $.797 * *$ & $.242^{* *}$ & $.306 * *$ & $.803 * *$ & $.124 * *$ & $.321 * *$ & -.001 & $.222 * *$ & $.768 * *$ & $-.220 * *$ & $.330 * *$ & $-.195 *$ & $.235 * *$ \\
\hline Dedication 5 & $.518 * *$ & $.349 * *$ & $.610 * *$ & $.549 * *$ & $.284 * *$ & $.617 * *$ & $.832 * *$ & .046 & $.373 * *$ & $.308 * *$ & $.243 * *$ & $.884 * *$ & $-.201 * *$ & $.312 * *$ & $.304 * *$ & $.175^{* *}$ \\
\hline$\omega$ & & .641 & & & .604 & & & & .648 & & & & & .672 & & \\
\hline Absorption 1 & $.791 * *$ & $.106^{*}$ & $.362 * *$ & $.765 * *$ & $.181 * *$ & $.383 * *$ & $.647 * *$ & -.048 & .045 & $.094 *$ & $.292 * *$ & $.739 * *$ & $.135 * *$ & -.048 & $.151 *$ & $.386 * *$ \\
\hline Absorption 2 & $.627 * *$ & $.302 * *$ & $.516^{* *}$ & $.651 * *$ & $.474 * *$ & $.352 * *$ & $.519 * *$ & -.006 & -.004 & $.273 * *$ & $.494 * *$ & $.570 * *$ & .018 & -.043 & $.337 * *$ & $.445 * *$ \\
\hline Absorption 3 & $.769 * *$ & $.088 *$ & $.401 * *$ & $.792 * *$ & .034 & $.372 * *$ & $.684 * *$ & .010 & .017 & .043 & $.233 * *$ & $.723 * *$ & .061 & .024 & -.113 & $.364 * *$ \\
\hline Absorption 4 & $.827 * *$ & $.194 * *$ & $.279 * *$ & $.843 * *$ & $.198 * *$ & $.249 * *$ & $.552 * *$ & $.165^{* *}$ & $.159 * *$ & .108 & $.610 * *$ & $.624 * *$ & $-.197 * *$ & .073 & .010 & $.565 * *$ \\
\hline Absorption 5 & $.657 * *$ & $.572 * *$ & $.241 * *$ & $.677 * *$ & $.407 * *$ & $.376 * *$ & $.510 * *$ & $.106 * *$ & .048 & $.534 * *$ & $.628 * *$ & $.583 * *$ & $-.116 * *$ & -.034 & $.315 * *$ & $.615 * *$ \\
\hline Absorption 6 & $.350 * *$ & $.333 * *$ & $.767 * *$ & $.381 * *$ & $.352 * *$ & $.731 * *$ & $.355 * *$ & .025 & $.196 * *$ & $.332 * *$ & $.725 * *$ & $.397 * *$ & -.104 & $.214 * *$ & $.420 * *$ & $.609 * *$ \\
\hline$\omega$ & .955 & .498 & & .961 & .524 & & .958 & & & .391 & & .964 & & & .378 & \\
\hline
\end{tabular}

Note. $* p<.05 ; * * p<.01$; CFA: Confirmatory factor analysis; ESEM: Exploratory structural equation modeling; G- $\lambda$ : Standardized factor loading on the global factor; S- $\lambda$ : Standardized factor loading on one of the specific factors; $\delta$ : Standardized item uniqueness; bold: Target factor loadings in the ESEM solutions; $\omega$ : Omega coefficient of composite reliability. 
Table 3

Results from the Latent Profile and Latent Transition Analysis Models

\begin{tabular}{|c|c|c|c|c|c|c|c|c|}
\hline Model & LL & $\# f p$ & Scaling & AIC & CAIC & BIC & $\mathrm{ABIC}$ & Entropy \\
\hline \multicolumn{9}{|l|}{ Final Latent Profile Analyses } \\
\hline Time 1 & -3499.635 & 28 & 1.469 & 7055.270 & 7211.876 & 7183.876 & 7094.967 & .788 \\
\hline Time 2 & -3391.380 & 28 & 1.339 & 6838.761 & 6995.366 & 6967.366 & 6878.457 & .820 \\
\hline \multicolumn{9}{|l|}{ Longitudinal Latent Profile Analyses } \\
\hline Configural & -6891.016 & 56 & 1.404 & 13894.031 & 14207.242 & 14151.242 & 13973.424 & .804 \\
\hline Structural & -6899.661 & 36 & 2.623 & 13871.321 & 14072.671 & 14036.671 & 13922.359 & .783 \\
\hline Dispersion & -6900.555 & 32 & 2.781 & 13865.110 & 14044.088 & 14012.088 & 13910.477 & .784 \\
\hline Distributional & -6902.096 & 28 & 3.256 & 13860.192 & 14016.798 & 13988.798 & 13899.889 & .781 \\
\hline Latent Transition Analysis & -961.603 & 24 & 375 & 1971.207 & 2105.440 & 2081.440 & 2005.232 & 901 \\
\hline \multicolumn{9}{|l|}{ Predictive Similarity (Demographics) } \\
\hline Null Effects Model & -3293.969 & 33 & .581 & 6653.938 & 6838.509 & 6805.509 & 6700.723 & .900 \\
\hline Profile-Specific Free Relations with Predictors & -3265.355 & 117 & 1.824 & 6764.710 & 7419.096 & 7302.096 & 6930.584 & .895 \\
\hline Free Relations with Predictors & -3274.078 & 57 & .552 & 6662.156 & 6980.959 & 6923.959 & 6742.966 & .903 \\
\hline Equal Relations with Predictors & -3288.422 & 45 & 677 & 6666.843 & 6918.530 & 6873.530 & 6730.641 & 900 \\
\hline \multicolumn{9}{|l|}{ Explanatory Similarity } \\
\hline Free Relations with Outcomes & -6824.261 & 72 & 2.839 & 13792.521 & 14195.220 & 14123.220 & 13894.597 & 908 \\
\hline Equal Relations with Outcomes & -6830.974 & 52 & 1.697 & 13765.949 & 14056.787 & 14004.787 & 13839.670 & 908 \\
\hline
\end{tabular}

Note. LL: Model loglikelihood; \#fp: Number of free parameters; scaling: Scaling correction factor associated with robust maximum likelihood estimates; AIC: Akaïke information criteria; CAIC: Constant AIC; BIC: Bayesian information criteria; ABIC: Sample size adjusted BIC; aLMR: Adjusted Lo-Mendel-Rubin likelihood ratio test; BLRT: Bootstrap likelihood ratio test. 
Table 4

Transitions Probabilities for the Final Latent Transition Analysis Model

\begin{tabular}{llllll}
\hline & Profile 1 & Profile 2 & Profile 3 & Profile 4 & Profile \\
\hline Time 1 & & & & & \\
Profile 1 & 1.000 & 0 & 0 & 0 & 0 \\
Profile 2 & 0 & 1.000 & 0 & 0 & 0 \\
Profile 3 & 0 & 0 & .929 & 0 & .022 \\
Profile 4 & 0 & .048 & 0 & .926 & .074 \\
Profile 5 & .020 & 0 & .046 & 0 & .933
\end{tabular}

Note. Profile 1: engaged yet distanced profile; Profile 2: normative profile; Profile 3: vigorously absorbed profile; Profile 4: disengaged-vigorous profile; and Profile 5: totally disengaged profile.

Table 5

Time-Invariant Associations between Profile Membership and the Outcomes

\begin{tabular}{|c|c|c|c|c|c|c|}
\hline & $\begin{array}{c}\text { Profile } 1 \\
\mathrm{M}[\mathrm{CI}]\end{array}$ & $\begin{array}{c}\text { Profile } 2 \\
\mathrm{M}[\mathrm{CI}]\end{array}$ & $\begin{array}{c}\text { Profile } 3 \\
\mathrm{M}[\mathrm{CI}]\end{array}$ & $\begin{array}{l}\text { Profile } 4 \\
\mathrm{M}[\mathrm{CI}]\end{array}$ & $\begin{array}{l}\text { Profile } 5 \\
\mathrm{M}[\mathrm{CI}]\end{array}$ & $\begin{array}{c}\text { Summary of } \\
\text { Differences }(p \leq .05)\end{array}$ \\
\hline Stress & $1.670[1.423 ; 1.917]$ & $2.123[1.889 ; 2.356]$ & $2.847[2.059 ; 3.634]$ & $3.128[2.866 ; 3.390]$ & $2.454[2.242 ; 2.667]$ & $\begin{array}{l}4>5>2>1 ; 3>1 ; \\
4=3 ; 2=3 ; 5=3\end{array}$ \\
\hline Intentions to quit* & $-1.204[-1.289 ;-1.120]$ & $-.428[-.706 ;-.151]$ & $.302[-.849 ; 1.452]$ & $1.208[1.048 ; 1.369]$ & $.706[.460 ; .951]$ & $\begin{array}{l}4>5>2>1 ; 3>1 ; \\
4=3 ; 2=3 ; 5=3\end{array}$ \\
\hline Job Satisfaction* & $1.170[1.098 ; 1.243]$ & $.530[.286 ; .774]$ & $-.138[-.685 ; .410]$ & $-1.488[-1.761 ;-1.216]$ & $-.829[-1.254 ;-.403]$ & $1>2>3>5>4$ \\
\hline Health* & $.960[.446 ; 1.473]$ & $.250[.102 ; .399]$ & $-.266[-.661 ; .129]$ & $-.878[-1.062 ;-.695]$ & $-.373[-.591 ;-.155]$ & $1>2>3=5>4$ \\
\hline
\end{tabular}

Note. M: Mean; CI: 95\% confidence interval; * Variables estimated from factor scores with mean of 0 and a standard deviation of 1; Profile 1: engaged yet distanced profile; Profile 2: normative profile; Profile 3: vigorously absorbed profile; Profile 4: disengaged-vigorous profile; and Profile 5: totally disengaged profile. 
Online Supplemental Materials for:

\section{Complementary Variable- and Person-Centered Approaches to the Dimensionality of Work}

\section{Engagement: A Longitudinal Investigation}

\begin{tabular}{l} 
Authors' note: \\
$\begin{array}{l}\text { These online technical appendices are to be posted on the journal website and hot-linked to the manuscript. } \\
\text { If the journal does not offer this possibility, these materials can alternatively be posted on one of our } \\
\text { personal websites (we will adjust the in-text reference upon acceptance). } \\
\text { We would also be happy to have some of these materials brought back into the main manuscript, or } \\
\text { included as published appendices if you deem it useful. We developed these materials to provide additional } \\
\text { technical information and to keep the main manuscript from becoming needlessly long. }\end{array}$ \\
\hline
\end{tabular}




\section{Table S1}

Goodness-of-Fit Statistics and Information Criteria for the Outcomes Measurement Models.

\begin{tabular}{lcccccccccc}
\hline Model & $\chi^{2}$ & $\mathrm{df}$ & CFI & TLI & RMSEA RMSEA 90\% CI & $\Delta \chi^{2}(d f)$ & $\Delta$ CFI & $\Delta$ TLI & $\Delta$ RMSEA \\
\hline M7. Configural invariance (no ETEC) & $380.718^{*}$ & 111 & .964 & .950 & .058 & {$[.051 ; .064]$} & - & - & - & - \\
M8. Weak invariance (no ETEC) & $387.730^{*}$ & 117 & .963 & .952 & .056 & {$[.050 ; .063]$} & $2.552(6)$ & -.001 & -.001 & +.002 \\
M9. ETEC & $389.634^{*}$ & 118 & .963 & .952 & .056 & {$[.050 ; .062]$} & $1.838(1)$ & .000 & .000 & .000 \\
M10. Strong invariance & $408.415^{*}$ & 124 & .962 & .953 & .056 & {$[.050 ; .062]$} & $18.507(6)$ & -.001 & -.001 & +.001 \\
M11. Strict invariance & $415.977^{*}$ & 133 & .962 & .956 & .054 & {$[.048 ; .060]$} & $15.353(9)$ & .000 & .000 & +.003 \\
M12. Var-Cov invariance & $421.156^{*}$ & 139 & .962 & .958 & .053 & {$[.047 ; .059]$} & $.622(6)$ & .000 & .000 & +.002 \\
M13. Latent means invariance & $423.639^{*}$ & 142 & .962 & .959 & .052 & {$[.046 ; .058]$} & $1.411(3)$ & .000 & .000 & +.001 \\
\hline
\end{tabular}

Note. ${ }^{*} p<.01$; df: Degrees of freedom; CFI: Comparative fit index; TLI: Tucker-Lewis index; RMSEA: Root mean square error of approximation; CI = Confidence interval; $\Delta$ : Change in fit relative to the preceding model in the sequence; ETEC: Essentially tau-equivalent constraint.

\section{Table S2}

Standardized Factor Loadings $(\lambda)$ and Uniquenesses $(\delta)$ for the M13 solution (Latent Means Invariance)

\begin{tabular}{lcccc}
\hline & $\begin{array}{c}\text { Intentions to quit } \\
\text { Items }\end{array}$ & $\begin{array}{c}\text { Job satisfaction } \\
\lambda\end{array}$ & $\begin{array}{c}\text { Health } \\
\lambda\end{array}$ & $\delta$ \\
\hline Intentions to quit & & & & \\
$\quad$ Item 1 & $.844^{*}$ & & & $.288^{*}$ \\
Item 2 & $.937^{*}$ & & $.122^{*}$ \\
Item 3 & $.936^{*}$ & & $.125^{*}$ \\
Job satisfaction & & & & $.252^{*}$ \\
Item 1 & & $.965^{*}$ & & $.127^{*}$ \\
Item 2 & & $.898^{*}$ & & $.194^{*}$ \\
Item 3 & & $.814^{*}$ & & $.338^{*}$ \\
Item 4 & & & & $.709^{*}$ \\
Health & & & $.540^{*}$ & $.612^{*}$ \\
Item 1 & & .934 & .506 & \\
Item 2 & & & & \\
0 & & & & \\
\hline Factor Correlations & Intentions to quit & Job satisfaction & Health & \\
Intentions to quit & & & & \\
Job satisfaction & $-.740^{*}$ & & & \\
Health & $-.398^{*}$ & $.471^{*}$ & & \\
\hline
\end{tabular}

Note. $* p<.01 . \lambda$ : Standardized factor loading; $\delta$ : Standardized item uniqueness; $\omega$ : omega coefficient of composite reliability. 
Table S3

Correlations between Variables

\begin{tabular}{|c|c|c|c|c|c|c|c|c|c|c|c|c|c|c|c|c|c|c|}
\hline & 1 & 2 & 3 & 4 & 5 & 6 & 7 & 8 & 9 & 10 & 11 & 12 & 13 & 14 & 15 & 16 & 17 & 18 \\
\hline 1. Sex & - & & & & & & & & & & & & & & & & & \\
\hline 2. Age & $-.080^{*}$ & - & & & & & & & & & & & & & & & & \\
\hline 3. Organizational tenure & -.012 & $.520^{* *}$ & - & & & & & & & & & & & & & & & \\
\hline 4. Global Engagement (T1) $\dagger$ & -.008 & .030 & -.007 & - & & & & & & & & & & & & & & \\
\hline 5. Specific Vigor(T1) $\dagger$ & .056 & $.094^{*}$ & .074 & 0 & - & & & & & & & & & & & & & \\
\hline 6. Specific Dedication (T1) $\dagger$ & $-.122^{* *}$ & .059 & $.092^{*}$ & 0 & 0 & - & & & & & & & & & & & & \\
\hline 7. Specific Absorption (T1) $\dagger$ & -.029 & .069 & .064 & 0 & 0 & 0 & - & & & & & & & & & & & \\
\hline 8. Intentions to Quit (T1) $\dagger$ & -.014 & -.065 & -.039 & $-.517^{* *}$ & $.202^{* *}$ & $-.261^{* *}$ & $.125^{* *}$ & - & & & & & & & & & & \\
\hline 9. Job Satisfaction (T1) $\dagger$ & -.032 & $-.083^{*}$ & $-.097^{*}$ & $.687^{* *}$ & $-.239^{* *}$ & $.264^{* *}$ & $-.121^{* *}$ & $-.779^{* *}$ & - & & & & & & & & & \\
\hline 10. Health $(\mathrm{T} 1) \dagger$ & .057 & $-.096^{*}$ & -.073 & $.504^{* *}$ & $-.181^{* *}$ & .057 & $-.160^{* *}$ & $-.528^{* *}$ & $.615^{* *}$ & - & & & & & & & & \\
\hline 11. Stress (T1) & -.060 & $.103^{* *}$ & $.093^{*}$ & $-.254^{* *}$ & $.182^{* *}$ & $.155^{* *}$ & $.311^{* *}$ & $.340^{* *}$ & $-.425^{* *}$ & $-.428^{* *}$ & - & & & & & & & \\
\hline 12. Global Engagement (T2)† & -.015 & .016 & .003 & $.879^{* *}$ & -.044 & $.105^{* *}$ & .052 & $-.478^{* *}$ & $.625^{* *}$ & $.480^{* *}$ & $-.204^{* *}$ & - & & & & & & \\
\hline 13. Specific Vigor(T2)† & .032 & $.090^{*}$ & $.087^{*}$ & -.042 & $.824^{* *}$ & .024 & .026 & $.143^{* *}$ & $-.180^{* *}$ & $-.142^{* *}$ & $.149^{* *}$ & 0 & - & & & & & \\
\hline 14. Specific Dedication (T2) $\dagger$ & $-.116^{* *}$ & .048 & $.108^{* *}$ & -.028 & $-.195^{*}$ & $.927^{* *}$ & $-.082^{*}$ & $-.206^{* *}$ & $.190^{* *}$ & .021 & $.151^{* *}$ & 0 & 0 & - & & & & \\
\hline 15. Specific Absorption (T2) $\dagger$ & -.028 & .075 & $.081^{*}$ & -.070 & $.141^{* *}$ & .072 & $.877^{* *}$ & $.168^{* *}$ & $-.178^{* *}$ & $-.198^{* *}$ & $.365^{* *}$ & 0 & 0 & 0 & - & & & \\
\hline 16. Intentions to Quit (T2) $\dagger$ & -.041 & $-.084^{*}$ & -.056 & $-.469^{* *}$ & $.150^{* *}$ & $-.220^{* *}$ & $.127^{* *}$ & $.835^{* *}$ & $-.620^{* *}$ & $-.504^{* * *}$ & $.295^{* *}$ & $-.543^{* *}$ & $.116^{* *}$ & $-.205^{* *}$ & $.149^{* *}$ & - & & \\
\hline 17. Job Satisfaction (T2) $\dagger$ & -.015 & $-.075^{*}$ & $-.085^{*}$ & $.648^{* *}$ & $-.223^{* *}$ & $.241^{* *}$ & $-.127^{* *}$ & $-.728^{* *}$ & $.890^{* *}$ & $.613^{* *}$ & $-.408^{* *}$ & $.712^{* *}$ & $-.178^{* *}$ & $.202^{* *}$ & $-.168^{* *}$ & $-.777^{* *}$ & - & \\
\hline 18. Health $(\mathrm{T} 2) \dagger$ & .074 & $-.091^{*}$ & -.058 & $.451^{* *}$ & $-.170^{* *}$ & .054 & $-.107^{* *}$ & $-.438^{* *}$ & $.509^{* *}$ & $.869^{* * *}$ & $-.375^{* *}$ & $.510^{* *}$ & $-.149^{* *}$ & .017 & $-.137^{* *}$ & $-.538^{* *}$ & $.627^{* *}$ & - \\
\hline 19. Stress (T2) & .001 & .044 & $.103^{*}$ & $-.246^{* *}$ & $.192^{* *}$ & $.124^{* *}$ & $-.308^{* *}$ & $.371^{* * *}$ & $-.375^{* *}$ & $-.405^{* * *}$ & $.663^{* *}$ & $-.250^{* *}$ & $.161^{* *}$ & $.133^{* *}$ & $.368^{* *}$ & $.403^{* *}$ & $-.440^{* *}$ & $-.421^{* *}$ \\
\hline
\end{tabular}
Note. $* p<.05 ; * * p<.01 ; \uparrow$ Variables estimated from factor scores with mean of 0 and a standard deviation of 1 . Gender was coded 0 for women and 1 for men. 
Table S4

Standardized Factor Loadings $(\lambda)$ and Uniquenesses $(\delta)$ for the first-order CFA and ESEM Solutions at Time 1 and 2

\begin{tabular}{|c|c|c|c|c|c|c|c|c|c|c|c|c|}
\hline \multirow[b]{2}{*}{ Items } & \multicolumn{2}{|c|}{ CFA Time 1} & \multicolumn{2}{|c|}{ CFA Time 2} & \multicolumn{4}{|c|}{ ESEM Time 1} & \multicolumn{4}{|c|}{ ESEM Time 2} \\
\hline & $\lambda$ & $\delta$ & $\lambda$ & $\delta$ & $\lambda$ & $\Lambda$ & $\lambda$ & $\delta$ & $\lambda$ & $\lambda$ & $\lambda$ & $\delta$ \\
\hline Vigor 1 & $.808 * *$ & $.348 * *$ & $.806 * *$ & $.350 * *$ & $.773 * *$ & .160 & $-.154 * *$ & $.286^{* *}$ & $.743 * *$ & .104 & .067 & $.274 * *$ \\
\hline Vigor 2 & $.877 * *$ & $.323 * *$ & $.879 * *$ & $.301 * *$ & $.840 * *$ & $.147 *$ & -.108 & $.316^{* *}$ & $.717 * *$ & .117 & .185 & $.247 * *$ \\
\hline Vigor 3 & $.764 * *$ & $.355^{* *}$ & $.774 * *$ & $.377 * *$ & $.382 * *$ & $.456 * *$ & -.028 & $.367 * *$ & $.549 * *$ & $.306 * *$ & .007 & $.385^{* *}$ \\
\hline Vigor 4 & $.607 * *$ & $.231 * *$ & $.696 * *$ & $.228 * *$ & $.524 * *$ & $-.204 *$ & $.568 * *$ & $.164 * *$ & .156 & .091 & $.649 * *$ & $.183 * *$ \\
\hline Vigor 5 & $.547 * *$ & $.193 * *$ & $.598 * *$ & $.186^{* *}$ & $.504 * *$ & -.14 & $.341 * *$ & $.200 * *$ & .165 & .048 & $.542 * *$ & $.190 * *$ \\
\hline Vigor 6 & $.500 * *$ & $.548 * *$ & $.564 * *$ & $.482 * *$ & $.392 * *$ & -.084 & $.373 * *$ & $.572 * *$ & .039 & .189 & $.471 * *$ & $.513 * *$ \\
\hline$\omega$ & .894 & & .906 & & .860 & & & & .758 & & & \\
\hline Dedication 1 & $.876^{* *}$ & $.198 * *$ & $.858 * *$ & $.172 * *$ & $.116^{*}$ & $.764 * *$ & .067 & $.176^{* *}$ & .072 & $.867 * *$ & -.076 & $.127 * *$ \\
\hline Dedication 2 & $.898 * *$ & $.417 * *$ & $.902 * *$ & $.400 * *$ & $.300 * *$ & $.621 * *$ & .065 & $.403 * *$ & $.382 * *$ & $.531 * *$ & .087 & $.360 * *$ \\
\hline Dedication 3 & $.895 * *$ & $.408 * *$ & $.910 * *$ & $.369 * *$ & .084 & $.808 * *$ & .088 & $.411 * *$ & $.191 *$ & $.863 * *$ & $-.123^{*}$ & $.379 * *$ \\
\hline Dedication 4 & $.823 * *$ & $.232 * *$ & $.836 * *$ & $.264 * *$ & .130 & $.578 * *$ & $.281 * *$ & $.224 * *$ & -.043 & $.721 * *$ & .241 & $.237 * *$ \\
\hline Dedication 5 & $.608 * *$ & $.257 * *$ & $.608 * *$ & $.228 * *$ & $-.257 * *$ & $.670 * *$ & $.368 * *$ & $.242 * *$ & $-.255^{* *}$ & $.667 * *$ & $.245^{*}$ & $.190 * *$ \\
\hline$\omega$ & .917 & & .922 & & & .890 & & & & .911 & & \\
\hline Absorption 1 & $.803 * *$ & $.632 * *$ & $.789 * *$ & $.516 * *$ & $.452 * *$ & $.323 * *$ & $.144 *$ & $.353 * *$ & $.482 * *$ & .130 & $.318 *$ & $.367 * *$ \\
\hline Absorption 2 & $.673 * *$ & $.630 * *$ & $.720 * *$ & $.630 * *$ & $.318 * *$ & $.227 * *$ & $.250 * *$ & $.513 * *$ & $.294 * *$ & .147 & $.389 *$ & $.509 * *$ \\
\hline Absorption 3 & $.769 * *$ & $.471 * *$ & $.794 * *$ & $.450 * *$ & $.490 * *$ & $.247 * *$ & $.149 *$ & $.425^{* *}$ & $.405 * *$ & $.261 * *$ & $.258 *$ & $.441 * *$ \\
\hline Absorption 4 & $.862 * *$ & $.701 * *$ & $.879 * *$ & $.642 * *$ & $.309 * *$ & $.387 * *$ & $.374 * *$ & $.605^{* *}$ & .143 & $.384 * *$ & $.505 * *$ & $.560 * *$ \\
\hline Absorption 5 & $.728 * *$ & $.750 * *$ & $.741 * *$ & $.682 * *$ & $.192 * *$ & $.295 * *$ & $.451 * *$ & $.649 * *$ & $.199 *$ & .162 & $.509 * *$ & $.600 * *$ \\
\hline Absorption 6 & $.410 * *$ & $.832 * *$ & $.439 * *$ & $.807 * *$ & $-.153^{*}$ & $.404 * *$ & $.299 * *$ & $.771 * *$ & -.160 & $.442 * *$ & .190 & $.759 * *$ \\
\hline$\omega$ & .818 & & .836 & & & & .456 & & & & .592 & \\
\hline
\end{tabular}

Note. $* p<.05 ; * * p<.01 ;$ CFA: Confirmatory factor analysis; ESEM: Exploratory structural equation modeling; $\lambda$ : Standardized factor loading; $\delta$ :

Standardized item uniqueness; bold: target factor loadings in the ESEM solutions; $\omega$ : Omega coefficient of composite reliability. 
Table S5

Latent Factor Correlations for the CFA and ESEM Solutions

\begin{tabular}{|c|c|c|c|c|c|c|}
\hline & \multicolumn{3}{|l|}{ CFA } & \multicolumn{3}{|l|}{ ESEM } \\
\hline & Vigor & Dedication & Absorption & & & \\
\hline \multicolumn{7}{|l|}{ Time 1} \\
\hline Vigor & - & & & - & & \\
\hline Dedication & .899 & - & & .743 & - & \\
\hline Absorption & .935 & .932 & - & .415 & .344 & - \\
\hline \multicolumn{7}{|l|}{ Time 2} \\
\hline Vigor & - & & & - & & \\
\hline Dedication & .928 & - & & .713 & - & \\
\hline Absorption & .933 & .921 & - & .398 & .651 & - \\
\hline
\end{tabular}

Note. All correlations are statistically significant $(p<.01)$ 


\section{Table S6}

Results from the Latent Profile Analysis Models

\begin{tabular}{|c|c|c|c|c|c|c|c|c|c|c|}
\hline Model & LL & $\# f p$ & Scaling & AIC & CAIC & BIC & ABIC & Entropy & aLMR & BLRT \\
\hline \multicolumn{11}{|l|}{ Time 1} \\
\hline 1 Profile & -3594.716 & 8 & 1.210 & 7205.431 & 7250.175 & 7242.175 & 7216.773 & $\mathrm{Na}$ & $\mathrm{Na}$ & $\mathrm{Na}$ \\
\hline 2 Profiles & -3568.684 & 13 & 1.909 & 7163.369 & 7236.078 & 7223.078 & 7181.799 & .795 & .5658 & $<.001$ \\
\hline 3 Profiles & -3538.377 & 18 & 1.362 & 7112.754 & 7213.429 & 7195.429 & 7138.273 & .824 & $<.05$ & $<.001$ \\
\hline 4 Profiles & -3517.996 & 23 & 1.548 & 7081.991 & 7210.631 & 7187.631 & 7114.599 & .832 & .4463 & $<.001$ \\
\hline 5 Profiles & -3499.635 & 28 & 1.469 & 7055.270 & 7211.876 & 7183.876 & 7094.967 & .788 & .1625 & $<.001$ \\
\hline 6 Profiles & -3485.314 & 33 & 1.324 & 7036.627 & 7221.197 & 7188.197 & 7083.412 & .806 & .1673 & $<.001$ \\
\hline 7 Profiles & -3474.096 & 38 & 1.322 & 7024.191 & 7236.727 & 7198.727 & 7078.065 & .814 & .3681 & $<.001$ \\
\hline 8 Profiles & -3463.913 & 43 & 1.285 & 7013.825 & 7254.326 & 7211.326 & 7074.788 & .814 & .3681 & $<.001$ \\
\hline 9 Profiles & -3454.820 & 48 & 1.252 & 7005.640 & 7274.106 & 7226.106 & 7073.691 & .819 & .5073 & .0400 \\
\hline 10 Profiles & -3445.971 & 53 & 1.212 & 6997.942 & 7294.374 & 7241.374 & 7073.082 & .817 & .3867 & .2667 \\
\hline \multicolumn{11}{|l|}{ Time 2} \\
\hline 1 Profile & -3468.928 & 8 & 1.251 & 6953.855 & 6998.600 & 6990.600 & 6965.197 & $\mathrm{Na}$ & $\mathrm{Na}$ & $\mathrm{Na}$ \\
\hline 2 Profiles & -3445.385 & 13 & 1.452 & 6916.770 & 6989.480 & 6976.480 & 6935.201 & .881 & .1821 & $<.001$ \\
\hline 3 Profiles & -3422.555 & 18 & 1.222 & 6881.110 & 6981.785 & 6963.785 & 6906.629 & .789 & .0049 & $<.001$ \\
\hline 4 Profiles & -3407.447 & 23 & 1.440 & 6860.894 & 6989.534 & 6966.534 & 6893.501 & .815 & .5188 & $<.001$ \\
\hline 5 Profiles & -3391.380 & 28 & 1.339 & 6838.761 & 6995.366 & 6967.366 & 6878.457 & .820 & .2300 & $<.001$ \\
\hline 6 Profiles & -3374.254 & 33 & 1.433 & 6814.509 & 6999.079 & 6966.079 & 6861.294 & .815 & .4668 & $<.001$ \\
\hline 7 Profiles & -3360.257 & 38 & 1.422 & 6796.514 & 7009.050 & 6971.050 & 6850.388 & .823 & .4504 & $<.001$ \\
\hline 8 Profiles & -3349.660 & 43 & 1.396 & 6785.320 & 7025.821 & 6982.821 & 6846.282 & .827 & .4757 & .0632 \\
\hline 9 Profiles & -3338.687 & 48 & 1.322 & 6773.374 & 7041.840 & 6993.840 & 6841.424 & .832 & .3053 & .0128 \\
\hline 10 Profiles & -3328.366 & 53 & 1.282 & 6762.733 & 7059.164 & 7006.164 & 6837.872 & .822 & .3860 & $<.001$ \\
\hline
\end{tabular}

Note. LL: Model loglikelihood; \#fp: Number of free parameters; scaling: Scaling correction factor associated with robust maximum likelihood estimates; AIC: Akaike information criteria; CAIC: Constant AIC; BIC: Bayesian information criteria; ABIC: Sample size adjusted BIC; aLMR: Adjusted Lo-Mendel-Rubin likelihood ratio test; BLRT: Bootstrap likelihood ratio test. 


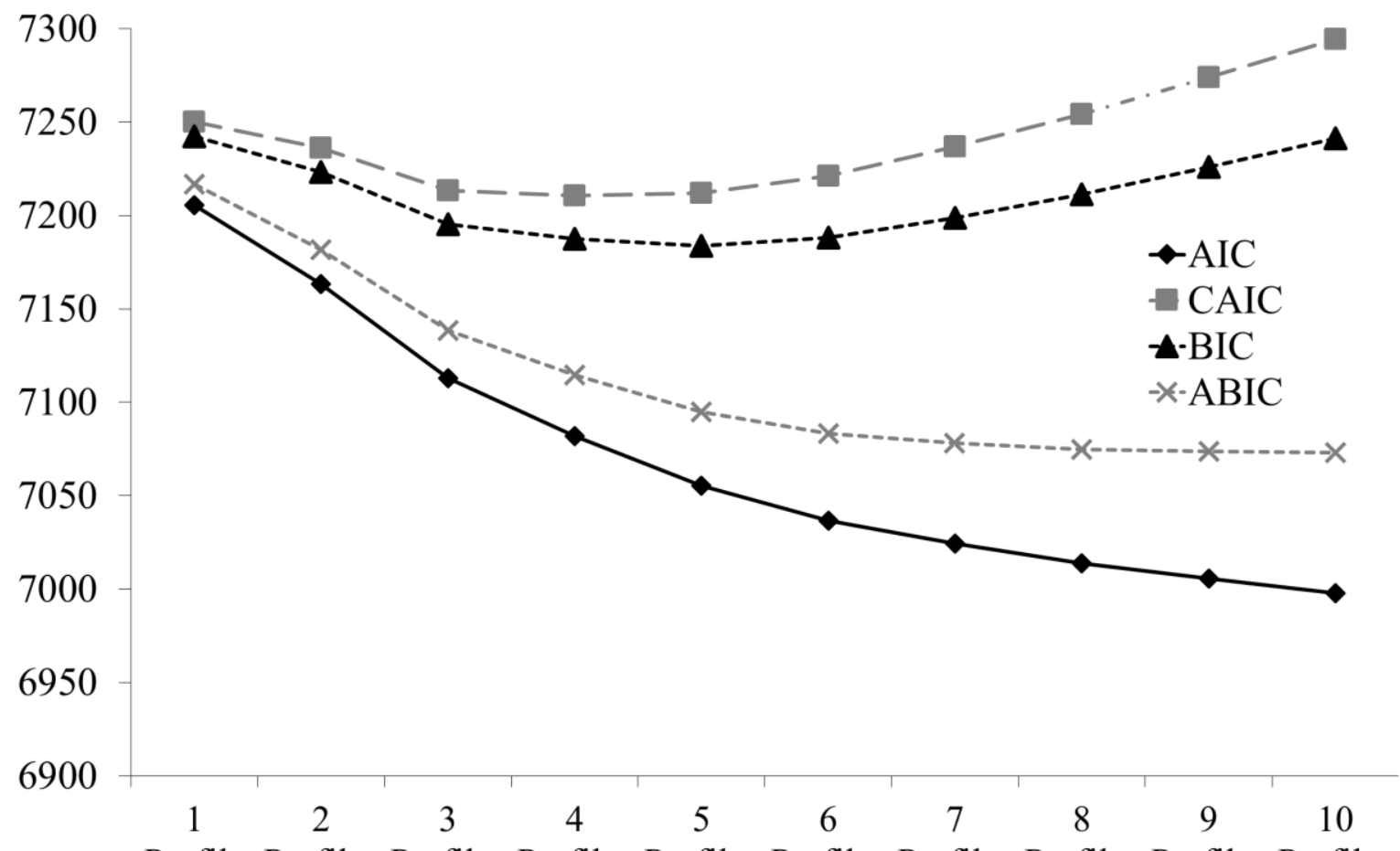

Profile Profiles Profiles Profiles Profiles Profiles Profiles Profiles Profiles Profiles

\section{Figure S1}

Elbow Plot of the Value of the Information Criteria for Solutions Including Different Number of Latent Profiles at Time 1

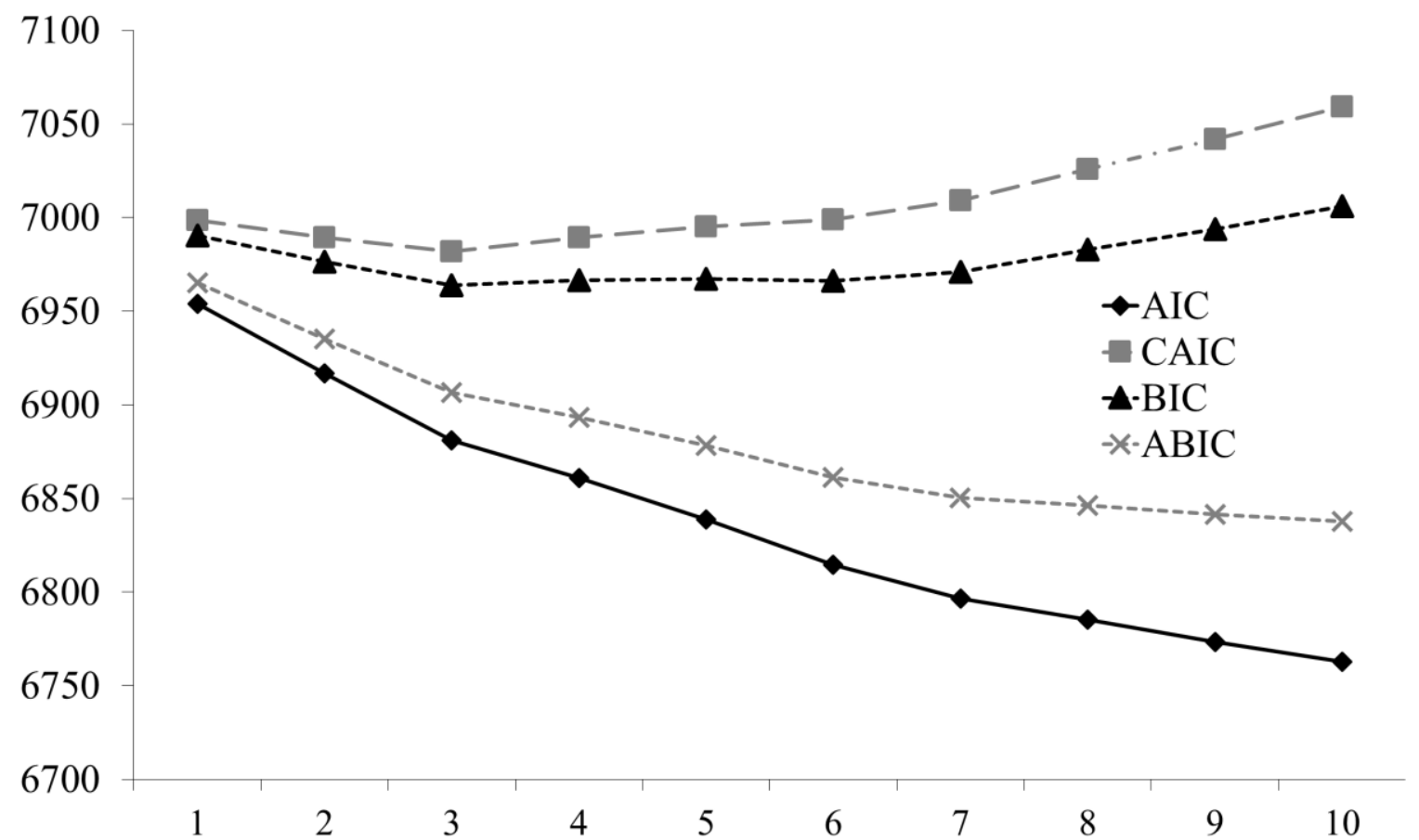

Profile Profiles Profiles Profiles Profiles Profiles Profiles Profiles Profiles Profiles

\section{Figure S2}

Elbow Plot of the Value of the Information Criteria for Solutions Including Different Number of Latent Profiles at Time 2 
Table S7

Detailed Parameter Estimates from the Final LPA Solution (Distributional Similarity)

\begin{tabular}{|c|c|c|c|c|c|c|}
\hline & $\begin{array}{c}\text { Profile } 1 \\
\text { Mean }[\mathrm{CI}]\end{array}$ & $\begin{array}{c}\text { Profile } 2 \\
\text { Mean }[\mathrm{CI}]\end{array}$ & $\begin{array}{c}\text { Profile } 3 \\
\text { Mean }[\mathrm{CI}]\end{array}$ & $\begin{array}{c}\text { Profile } 4 \\
\text { Mean }[\mathrm{CI}]\end{array}$ & $\begin{array}{c}\text { Profile } 5 \\
\text { Mean }[\mathrm{CI}]\end{array}$ & e [CI] \\
\hline at & $.253[-1.937 ; 2.444]$ & $.192[.075 ; .309]$ & $-.239[-.506 ; .028]$ & $-.479[-.916 ;-.042]$ & $-1.399[-1.712 ;-1$. & $.718[.586 ; .851]$ \\
\hline Specific Vigor & $.349[-.874 ; 1.572]$ & $-.132[-.276 ; .012]$ & $1.033[.742 ; 1.324]$ & $1.028[.473 ; 1.582]$ & $-.850[-1.205 ;-.495]$ & $.377[.286 ; .469]$ \\
\hline Specific Dedication & $.685[-1.356 ; 2.726]$ & $.058[-.042 ; .158]$ & $.250[-.293 ; .792]$ & $-1.015[-1.862 ;-.167]$ & $-.215[-.562 ; .132]$ & $.536[.235 ; .837]$ \\
\hline Specific Absorption & $-1.567[-4.099 ; .966]$ & $.002[-.106 ; .110]$ & $1.179[.901 ; 1.457]$ & $-.298[-.849 ; .253]$ & $-.207[-.416 ; .002]$ & $.339[.245 ; .434]$ \\
\hline
\end{tabular}

Note. $\mathrm{CI}=95 \%$ confidence interval. The profile indicators are estimated from factor scores with mean of 0 and a standard deviation of 1; Profile 1: engaged yet distanced profile; Profile 2: normative profile; Profile 3: vigorously absorbed profile; Profile 4: disengaged-vigorous profile; and Profile 5: totally disengaged profile.

\section{Table S8}

Classification Accuracy: Average Probability of Membership into Each Latent Profile (Column) as a Function of the Most Likely Profile Membership (Row).

\begin{tabular}{|c|c|c|c|c|c|}
\hline & Profile 1 & Profile 2 & Profile 3 & Profile 4 & Profile 5 \\
\hline \multicolumn{6}{|l|}{ Time 1} \\
\hline Profile 1 & .786 & .156 & 0 & .038 & .011 \\
\hline Profile 2 & .016 & .889 & .023 & .032 & .040 \\
\hline Profile 3 & 0 & .216 & .814 & .041 & .001 \\
\hline Profile 4 & .009 & .144 & .036 & .788 & .010 \\
\hline Profile 5 & .007 & .164 & .016 & .006 & .756 \\
\hline \multicolumn{6}{|l|}{ Time 2} \\
\hline Profile 1 & .761 & .214 & .007 & .022 & .002 \\
\hline Profile 2 & .013 & .900 & .021 & .031 & .035 \\
\hline Profile 3 & 0 & .243 & .786 & .044 & .002 \\
\hline Profile 4 & .016 & .168 & .033 & .729 & .008 \\
\hline Profile 5 & .001 & .208 & .004 & .010 & .742 \\
\hline
\end{tabular}

Note. Profile 1: engaged yet distanced profile; Profile 2: normative profile; Profile 3: vigorously absorbed profile; Profile 4: disengaged-vigorous profile; and Profile 5: totally disengaged profile. 